\title{
Evaluation of Cirrus Parameterizations for Radiative Flux Computations in Climate Models Using TOVS-ScaRaB Satellite Observations
}

\author{
C. J. Stubenrauch and F. Eddounia \\ CNRS/IPSL Laboratoire de Météorologie Dynamique, Ecole Polytechnique, Palaiseau, France \\ J. M. EDWARDS \\ Met Office, Exeter, United Kingdom
}

A. MACKE

Institute for Marine Research, Kiel, Germany

(Manuscript received 2 June 2006, in final form 21 December 2006)

\begin{abstract}
Combined simultaneous satellite observations are used to evaluate the performance of parameterizations of the microphysical and optical properties of cirrus clouds used for radiative flux computations in climate models. Atmospheric and cirrus properties retrieved from Television and Infrared Observation Satellite (TIROS-N) Operational Vertical Sounder (TOVS) observations are given as input to the radiative transfer model developed for the Met Office climate model to simulate radiative fluxes at the top of the atmosphere (TOA). Simulated cirrus shortwave (SW) albedos are then compared to those retrieved from collocated Scanner for Radiation Budget ( $\mathrm{ScaRaB}$ ) observations. For the retrieval, special care has been given to angular direction models. Three parameterizations of cirrus ice crystal optical properties are represented in the Met Office radiative transfer model. These parameterizations are based on different physical approximations and different hypotheses on crystal habit. One parameterization assumes pristine ice crystals and two ice crystal aggregates. By relating the cirrus ice water path (IWP) retrieved from the effective infrared emissivity to the cirrus SW albedo, differences between the parameterizations are amplified. This study shows that pristine crystals seem to be plausible only for cirrus with IWP less than $30 \mathrm{~g} \mathrm{~m}^{-2}$. For larger IWP, ice crystal aggregates lead to cirrus SW albedos in better agreement with the observations. The data also indicate that climate models should allow the cirrus effective ice crystal diameter $\left(D_{e}\right)$ to increase with IWP, especially in the range up to $30 \mathrm{~g} \mathrm{~m}^{-2}$. For cirrus with IWP less than $20 \mathrm{~g} \mathrm{~m}^{-2}$, this would lead to SW albedos that are about 0.02 higher than the ones of a constant $D_{e}$ of $55 \mu \mathrm{m}$.
\end{abstract}

\section{Introduction}

Cirrus clouds cover about $30 \%$ of the globe (e.g., Wylie and Menzel 1999; Stubenrauch et al. 2006) and play an important role in the climate system. Owing to their complex microphysical characteristics (consisting of nonspherical ice crystals of various shapes and sizes), however, their physical and radiative properties are still not completely understood. Therefore many climate models still use ice spheres or hexagonal columns in the computation of cirrus radiative properties.

Corresponding author address: Claudia J. Stubenrauch, CNRS/ IPSL Laboratoire de Météorologie Dynamique, Ecole Polytechnique, F-91128 Palaiseau CEDEX, France.

E-mail: stubenrauch@lmd.polytechnique.fr
Nevertheless, the emitted longwave (LW) and reflected shortwave (SW) fluxes calculated in climate models are sensitive to the size and shape of ice crystals: in their study Kristjânsson et al. (2000) found changes of up to 10 and $25 \mathrm{~W} \mathrm{~m}^{-2}$ in the annual mean LW and SW fluxes at the top of the atmosphere (TOA) on introducing a more realistic treatment of ice crystals instead of representing ice crystals as spheres. For reliable predictions of climate change it is therefore essential to make realistic assumptions about ice crystal shapes and sizes in cirrus clouds and to calculate their radiative properties accurately.

Depending on the formation process of cirrus clouds [large-scale lifting in the midlatitudes (e.g., Ivanova et al. 2001) or convection in the Tropics (e.g., Stith et al. 
2002)], one expects a resulting difference in their microphysical properties. In general circulation models these microphysical properties, such as cirrus mean effective ice crystal diameter $\left(D_{e}\right)$, must be predicted from available macrophysical quantities, such as ice water path (IWP), winds, and cloud temperature, (e.g., McFarlane et al. 1992; Donner et al. 1997; Bony and Emanuel 2001). Most such relationships are based on data from only a few places on the earth and for very limited time periods (e.g., Heymsfield and Platt 1984; Mitchell et al. 1996, Korolev et al. 2001; Boudala et al. 2002; Garrett et al. 2003). Satellite observations allow a more comprehensive view of the validity of such correlations.

The objective of this article is to combine the available satellite data to assess the validity of such correlations on a global scale. Assuming a parameterization of the single scattering properties of ice crystals, an observed effective infrared (IR) emissivity constrains the relationship between IWP and $D_{e}$ to a simple monotonic function. Therefore a relationship between $D_{e}$ and the environment, such as an increase with IWP or temperature leads to a unique relationship between IWP and effective IR emissivity. Using then the IWP determined from the retrieved effective IR emissivity under the assumption of a specific $D_{e}$, the $\mathrm{SW}$ albedo is simulated and compared with the observed SW albedo at the same point and time. This analysis of consistency between the two spectral regions allows us to assess the plausibility of different parameterizations.

A simulation study of Edwards et al. (2007, Fig. 5) has shown that for cirrus with IWP $=55 \mathrm{~g} \mathrm{~m}^{-2}$ and $D_{e}$ $=40 \mu \mathrm{m}$, the ice aggregate single scattering schemes developed by Baran et al. (2001) and Baran (2003) provide a $5 \%$ smaller LW emissivity and a $2 \%$ larger SW albedo than the schemes for ice crystals of the shape of hexagonal columns developed by $\mathrm{Fu}$ (1996) and Fu et al. (1998). The difference in SW albedo can be explained by a smaller asymmetry of ice crystal aggregates whereas the difference in LW emissivity is linked to a lower extinction. By relating the cirrus IWP retrieved from the effective IR emissivity to the cirrus SW albedo, differences between the parameterizations will be amplified and therefore more apparent in the observations.

The satellite datasets are presented in section 2. Atmospheric temperature and humidity profiles as well as cirrus temperature and cirrus effective IR emissivity are provided by the Television and Infrared Observation Satellite (TIROS-N) Operational Vertical Sounder (TOVS) Path-B dataset (Scott et al. 1999; Stubenrauch et al. 2006). These parameters are used, together with assumptions about cirrus ice crystal sizes and shapes, in the Met Office radiative transfer model, described in section 3, to determine the cirrus SW albedos. These are then compared to $\mathrm{SW}$ albedos, determined from simultaneous Scanner for Radiation Budget (ScaRaB) observations of about 1600 single-layer cirrus over ocean. Special care has been given to angular corrections necessary to transform the measured SW reflectances into SW albedos. Therefore angular direction models (ADMs) have been developed using a neural network approach and Monte Carlo radiative transfer simulations, also described in section 2 . The analysis and results are shown in section 4 , and conclusions are drawn in section 5 .

\section{Data for analysis}

\section{a. Atmospheric and cirrus properties from TOVS data}

The TOVS system consists, in particular, of two sounders: the High Resolution Infrared Radiation Sounder (HIRS) with 19 IR spectral channels between 3.7 and $15 \mu \mathrm{m}$ and one visible (VIS) channel $(0.7 \mu \mathrm{m})$ and the Microwave Sounding Unit (MSU) with four microwave channels around $5 \mathrm{~mm}$. The TOVS Path-B dataset (Scott et al. 1999) provides atmospheric temperature and water vapor profiles, as well as cloud and surface properties at a spatial resolution of $1^{\circ}$ latitude $\times 1^{\circ}$ longitude, from 1987 to 1995 . Multispectral cloud detection makes simultaneous use of HIRS and MSU. Cloud pressure $p_{\text {cld }}$ and effective IR cloud emissivity $\varepsilon_{\mathrm{cld}}$ are retrieved by a weighted $\chi^{2}$ method, using five radiances along the $15-\mu \mathrm{m} \mathrm{CO}_{2}$ absorption band (Stubenrauch et al. 1999a). Cloud pressure is transformed into cloud temperature $T_{\text {cld }}$ by using the retrieved atmospheric temperature profiles. The relatively high spectral resolution of the HIRS instruments yields reliable cirrus properties, day and night (Stubenrauch et al. 1999b, 2006). Monthly mean atmospheric temperature and humidity profiles and $p_{\mathrm{cld}}$ and $\varepsilon_{\mathrm{cld}}$ are used as input to the radiative transfer computations described in section 3 . Here, $p_{\text {cld }}$ corresponds to a radiatively active altitude that is about the midlevel pressure of the clouds, as has been demonstrated in a study with quasi-simultaneous data from the Lidar In-Space Technology Experiment (LITE) onboard the space shuttle Discovery (Stubenrauch et al. 2005).

The radiative flux computations are performed for large-scale semitransparent cirrus: clouds with a horizontal extent of at least $1^{\circ}$ latitude $\times 1^{\circ}$ longitude, $p_{\text {cld }}$ $<440 \mathrm{hPa}$ and $0.50<\varepsilon_{\text {cld }}<0.85$ (corresponding to a VIS optical thickness $\tau_{\mathrm{VIS}}$ between 0.7 and 3.8). For these clouds bulk microphysical properties have also been retrieved, from HIRS NOAA-10 satellite obser- 
vations, using spectral cirrus emissivity differences between 11 and $8 \mu \mathrm{m}$ (Rädel et al. 2003; Stubenrauch et al. 2004). The global averages (from $60^{\circ} \mathrm{N}$ to $60^{\circ} \mathrm{S}$ ) of mean effective ice crystal diameter $D_{e}$ and IWP of these cirrus are $55 \mu \mathrm{m}$ and $30 \mathrm{~g} \mathrm{~m}^{-2}$.

\section{b. Cirrus SW albedo from ScaRaB data}

The ScaRaB radiometer on board the Russian $M e$ teor-3/7 satellite provided Earth Radiation Budget (ERB) observations from March 1994 to February 1995 (Kandel et al. 1998) at a spatial resolution of about 60 $\mathrm{km}$ (at nadir). The inclination of the orbit $\left(82.6^{\circ}\right)$ is such that all local hours are observed within 104 days. In addition to two broadband LW and SW channels for ERB observations, the ScaRaB instrument has two narrowband IR and VIS channels for improved cloud scene identification because the contrast between clouds and clear sky is larger for these narrowband atmospheric window channels than for the broadband channels (Stubenrauch et al. 1996, 2002).

The International Satellite Cloud Climatology Project (ISCCP) method for cloud detection and determination of cloud and surface properties makes use of the same narrowband channels as ScaRaB but is applied to a collection of measurements at a better spatial resolution of about $7 \mathrm{~km}$, from geostationary and polarorbiting satellites around the globe (Rossow and Schiffer 1999). This method was applied to the two ScaRaB narrowband radiances for cloud detection and for the determination of their properties (Briand 2000; Stubenrauch et al. 2002). For complementary cloud property information, the ScaRaB dataset was collocated with original ISCCP data during daytime. The good spatial resolution of the ISCCP dataset provides information on cloud heterogeneity within the $1^{\circ}$ latitude $\times 1^{\circ}$ longitude grid cells of the collocated dataset. The collocated ScaRaB-ISCCP dataset was used to develop improved SW ADMs for totally cloudy scenes (Briand 2000).

The fraction of solar radiation reflected by clouds depends on the one hand on the cloud physical properties, like their spatial extent, optical thickness, and microphysical composition (water or ice particles and their size distribution), and on the other hand on external parameters such as solar zenith angle $\theta_{0}$ as well as on the surface properties in the case of thin or broken clouds. Scanning radiometers such as the Earth Radiation Budget Experiment (ERBE), ScaRaB, and the Cloud and the Earth's Radiant Energy System (CERES) measure reflected radiances $L_{\mathrm{Sw}}\left(\theta_{0}, \theta_{v}, \phi\right)$ for a certain viewing geometry, with satellite viewing zenith angle $\theta_{v}$ and relative azimuth angle $\phi$. These radiances are converted into physical fluxes by integrating them over all upwelling directions, where ADMs account for the anisotropy of the underlying scene. The anisotropy function $R\left(\theta_{0}, \theta_{v}, \phi\right.$, scene $)$ corresponds to a reflectance and is defined as the ratio of Lambertian flux $\pi L_{\mathrm{SW}}\left(\theta_{0}, \theta_{v}, \phi\right)$ and the real flux

$$
R\left(\theta_{0}, \theta_{v}, \phi, \text { scene }\right)=\frac{\pi L_{\mathrm{SW}}\left(\theta_{0}, \theta_{v}, \phi\right)}{\int_{0}^{2 \pi} \int_{0}^{\pi / 2} L_{\mathrm{SW}}\left(\theta_{0}, \theta, \phi\right) \cos \theta \sin \theta d \theta d \phi}
$$

The cloud albedo $\alpha_{S W}$ is the ratio of reflected solar flux, corrected for anisotropy by $R\left(\theta_{0}, \theta_{v}, \phi\right.$, scene $)$, over incident solar flux $E_{0} \cos \theta_{0}$ :

$$
\alpha_{\mathrm{SW}}\left(\theta_{0}\right)=\frac{\pi L_{\mathrm{SW}}\left(\theta_{0}, \theta_{v}, \phi\right)}{R\left(\theta_{0}, \theta_{v}, \phi, \text { scene }\right) E_{0} \cos \theta_{0}},
$$

with $E_{0}$ the solar constant of $1368 \mathrm{~W} \mathrm{~m}^{-2}$, corrected for earth-sun distance by $(1-0.0336) \sin [0.986(N-93) \pi /$ $180]$, with $N$ the day of the year.

\section{1) Original angular DiRection MODElS}

Radiative fluxes in the original ScaRaB dataset (Viollier et al. 1995) were obtained by using ADMs developed for ERBE (Suttles et al. 1992). Biases in the ERBE ADMs have already been described in (e.g., Suttles et al. 1992; Li and Trishchenko 1999; Loeb et al.
2003; Loukachine and Loeb 2003). Here we test the self-consistency of ice cloud and water cloud SW albedos by comparing the difference between the SW average albedo over all ice cloud (or water cloud) scenes and over all angles $\theta_{0}$ at a specific viewing angle interval $\theta_{v}$ and the SW albedo averaged over all ice cloud (or water cloud) scenes and over all angles $\theta_{0}$ and $\theta_{v}$ for $\theta_{v}$ intervals between $-50^{\circ}$ and $50^{\circ}$. Negative $\theta_{v}$ corresponds to backscattering. Ice clouds and water clouds are distinguished by the average ISCCP cloud temperature with $T_{\text {cld }}<253 \mathrm{~K}$ and $T_{\text {cld }}>273 \mathrm{~K}$, respectively. For large enough statistics (leading on average to similar scenes in the $\theta_{v}$ intervals) and perfect ADMs this difference should be angle independent and 0 . This is not the case for the present data, as shown in Fig. 1a. SW albedo biases between forward and backward scattering reach 0.05 . In each of these $\theta_{v}$ intervals there are 
(a)

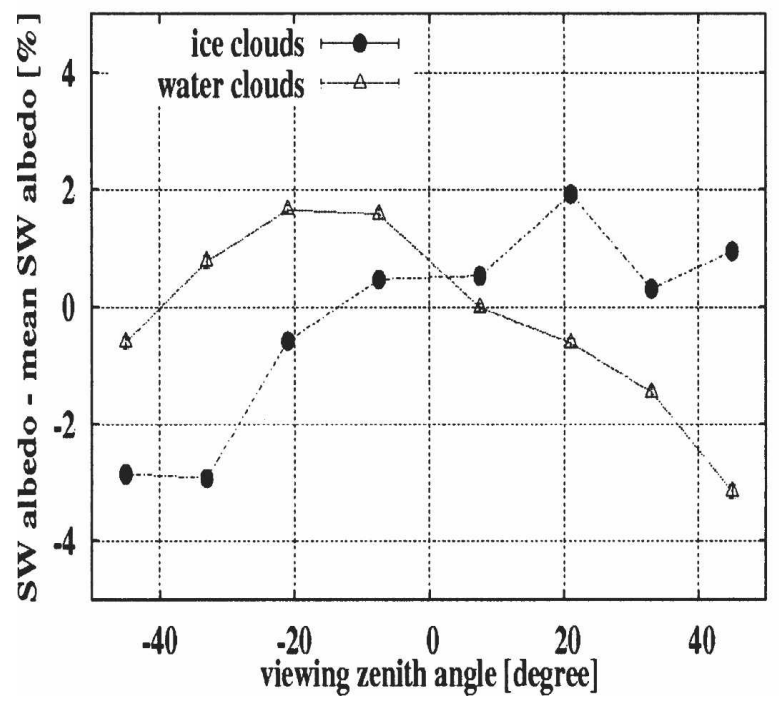

(b)

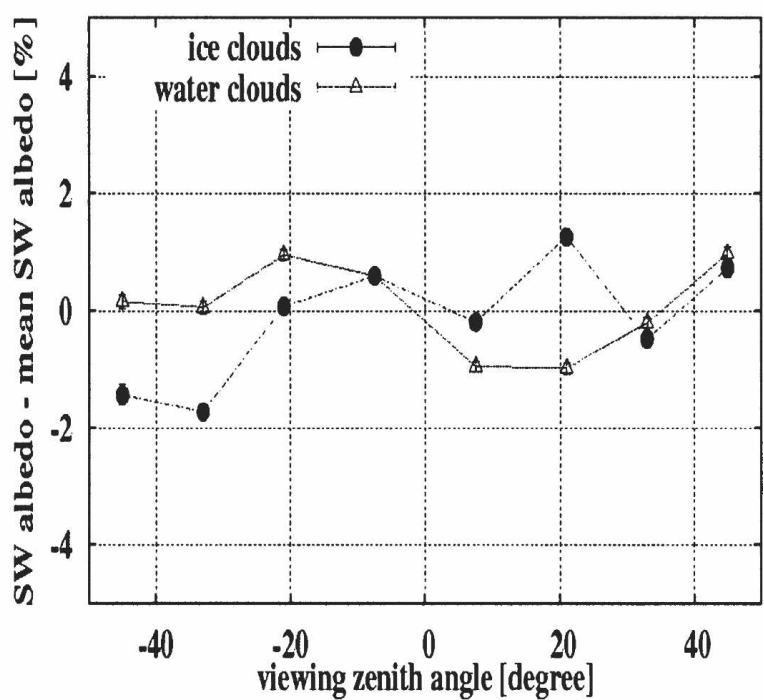

FIG. 1. The difference between the average ScaRaB SW albedo in a given viewing zenith angular bin and the SW albedo averaged over all angles as a function of viewing zenith angle separately for overcast scenes of water and ice clouds over ocean. For these figures the whole $\mathrm{ScaRaB}$ statistics was used with $\cos \theta_{0}$ ranging from 0.2 to 1 . Negative viewing zenith angles correspond to backscattering. (a) ERBE ADMs applied and (b) ADMs using a neural network technique, based on cloud phase, optical thickness, and IR heterogeneity, applied.

more than 100 points, with total statistics of about 12000 ice clouds and 15000 water clouds. To assure that the sun geometry and scene consistency of these clouds are equally distributed, we have investigated $\cos \theta_{0}$ and the relative $R_{\mathrm{Sw}}$ standard deviation of these clouds as function of $\theta_{v}$ separately for water and ice clouds. The relative $R_{\mathrm{SW}}$ standard deviation can be considered as a measure of scene homogeneity: for a class with similar angular dependence of $R_{\mathrm{SW}}$ this variable should depend only on $\theta_{0}$ (Briand 2000). The mean values of both variables are very similar within the different $\theta_{v}$ intervals (not shown), indicating that the statistics are well represented, and therefore the biases in Fig. 1 can be probably linked to the ERBE scene identification for the ADMs. It distinguishes four classes of cloud cover, from clear to overcast, using the assumption that clear scenes correspond to the warmest and darkest and overcast to the coldest and brightest scenes. Such a classification, for example, falsely identifies scenes of overcast water clouds as mostly cloudy scenes because overcast low water clouds do not correspond to the coldest scenes.

\section{2) IMPROVED ANGULAR DIRECTION MODELS}

Briand (2000) has developed ADMs, based on cloud properties such as phase, optical thickness, and IR heterogeneity, for overcast scenes (all ISCCP pixels cloudy within a $1^{\circ}$ latitude $\times 1^{\circ}$ longitude grid) over ocean.
Therefore cloud properties together with the observation geometry were integrated into a neural network (the Stuttgart Neural Network Simulator: Zell et al. $1995)$ to simulate the SW reflectances $R_{\mathrm{SW}}\left(\theta_{0}, \theta_{V}, \phi\right.$, cloud property). Shortwave reflectances were simulated separately for water and for ice clouds, using as cloud properties VIS optical thickness $\tau$ computed with the ISCCP algorithm from ScaRaB data and ScaRaB9 IR brightness temperature spatial heterogeneity (within the $1^{\circ}$ latitude $\times 1^{\circ}$ longitude grid boxes), scaled by the brightness temperature difference between clear sky and the observed scene. When using variables from ScaRaB data to describe the cloud properties, an additional neural network is necessary to take out residual angle dependence of the retrieved cloud properties (Briand 2000).

For the supervised training, using several months of ScaRaB data, the simulated SW reflectances were compared to the measured SW reflectances. The standard deviations of the differences between measured and simulated $R_{\mathrm{SW}}$ are $0.014 \mathrm{sr}^{-1}$ (4\%) for water clouds and $0.026 \mathrm{sr}^{-1}(6 \%)$ for ice clouds. The slightly larger standard deviation for ice clouds can be most probably explained by their more complicated microphysics (e.g., different ice crystal shapes). As an example Fig. 2 presents the ScaRaB SW ADMs in comparison to the ERBE ADMs for two types of cirrus $(\tau<4$ and $\tau>7)$ as a function of $\theta_{v}$, for a sun geometry close to the one 


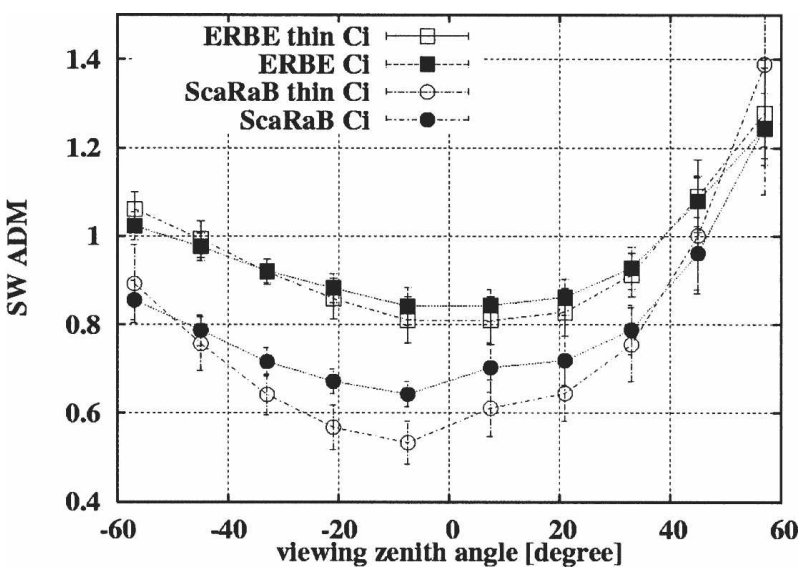

FIG. 2. Average ERBE and ScaRaB ADMs as a function of $\theta_{v}$, for overcast scenes of ice clouds over ocean, separately for thin cirrus (with $\tau<4$ ) and thick cirrus (with $\tau>7$ ), for a sun geometry close to the one of the collocated TOVS ScaRaB dataset $\left(\cos \theta_{0}\right.$ between 0.34 and 0.64 ).

in the collocated TOVS ScaRaB dataset (see section 2d). Whereas the ERBE ADMs are very similar for thin and thick cirrus, the ScaRab ADMs correct for a larger anisotropy in the case of thin cirrus, in agreement with Monte Carlo simulations (Schlimme et al. 2005) and other analyses (e.g., Loeb et al. 2000).

A partial SW albedo was then calculated by integrating the simulated SW reflectances over $\theta_{V} \in\left[0^{\circ}, 63^{\circ}\right]$ and $\phi \in\left[0^{\circ}, 360^{\circ}\right]$, normalized by the ratio of measured and simulated SW reflectance at the angular configuration $\left(\theta_{v}, \theta_{0}, \phi\right)$ of each measurement:

$\alpha_{\mathrm{SW}}^{\mathrm{sim}}\left(\theta_{v}<63^{\circ}, \theta_{0}\right)=\frac{2}{\pi} \int_{0}^{\pi} d \phi \int_{0}^{\theta_{\max }} d \theta_{v} R_{\mathrm{SW}}^{\mathrm{sim}} \cos \theta_{v} \sin \theta_{v}$

$\alpha_{\mathrm{SW}}\left(\theta_{v}<63^{\circ}, \theta_{0}\right)=\alpha_{\mathrm{SW}}^{\mathrm{sim}}\left(\theta_{v}<63^{\circ}, \theta_{0}\right) \frac{R_{\mathrm{SW}}^{\mathrm{meas}}\left(\theta_{v}, \theta_{0}, \phi\right)}{R_{\mathrm{SW}}^{\mathrm{sim}}\left(\theta_{v}, \theta_{0}, \phi\right)}$.

To extend to the full albedo, one has to evaluate the fraction of energy contained between $63^{\circ}$ and $90^{\circ}$. Therefore the ratio of total solar flux to partial flux has been computed from SW fluxes simulated by a Monte Carlo technique (Macke et al. 1995; Schlimme et al. 2005) as a function of $\theta_{0}$, cloud optical thickness $\tau$, and cloud phase. The Monte Carlo radiative transfer technique consists of illuminating the cloud by individual packages of solar photons. Scattering and absorption processes are simulated according to the Beer law of attenuation until the photon package escapes from the system or until it is fully absorbed. At each scattering location, the amount of radiation that can reach the detector (viewing direction) is calculated. Irregular
TABLE 1. Regression coefficients, in Eq. (3b), to determine ratios between total and partial SW albedo as a function of $\tau$.

\begin{tabular}{cccrcc}
\hline \hline$\tau$ & $c_{1}$ & $c_{2}$ & \multicolumn{1}{c}{$c_{3}$} & $c_{4}$ & $c_{5}$ \\
\hline 1.1 & 0.177 & 0.806 & 0.304 & 0.327 & 0.394 \\
2.6 & 0.333 & 0.930 & -0.203 & 0.013 & 0.916 \\
4.6 & 0.304 & 0.901 & -0.066 & 0.029 & 0.851 \\
\hline
\end{tabular}

polycrystals with $D_{e}=60 \mu \mathrm{m}$ have been chosen as ice microphysical properties.

For water clouds it has been parameterized as

$$
\frac{a 90^{\circ}}{a 63^{\circ}}{ }_{\text {water }}=1.44 \cos \theta_{0}^{2}-2.44 \cos \theta_{0}+2.33 .
$$

For ice clouds three classes of optical thickness have been distinguished:

$$
\frac{\alpha 90^{\circ}}{\alpha 63^{\circ}}{ }_{\text {ice }}-c_{1}(\tau)+\frac{c_{2}(\tau)}{\cos \left[c_{3}(\tau) \theta_{0}\right]}+\frac{c_{4}(\tau)}{\cos ^{2}\left[c_{5}(\tau) \theta_{0}\right]},
$$

with regression coefficients $c_{1}$ to $c_{5}$ presented in Table 1 .

Similar extension terms have been found by Bréon (1992) and by Loeb et al. (2000). Figure 3 presents this ratio of SW energy simulated for these three types of cirrus as a function of $\theta_{0}$. One concludes that about $23 \%-40 \%$ of SW energy is not observed by ScaRaB because of the limit on $\theta_{v}$. This fraction increases with $\theta_{0}$ and decreases with $\tau$. For comparison, the ERBE scan instrument with a $\theta_{v}$ maximum of $72^{\circ}$ does not observe $8 \%-25 \%$ of the SW energy (again depending on $\theta_{0}$ and $\tau$ ). Figure 4 summarizes the scheme of the cloud SW albedo computation from measured ScaRaB

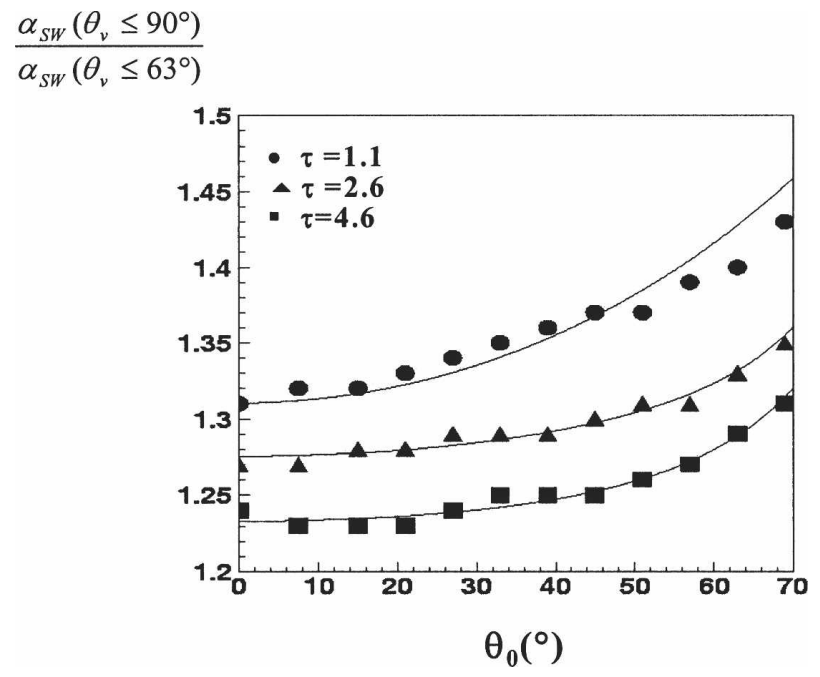

FIG. 3. Ratios of total and partial SW albedo as a function of solar zenith angle for three types of cirrus $(\tau=1.1, \tau=2.6$, and $\tau=4$.6). The ratios have been computed from Monte Carlo simulations assuming that the cirrus consists of ice crystal aggregates. Solid curves correspond to the fitted functions of Eq. (5b). 


\section{Albedo determination}

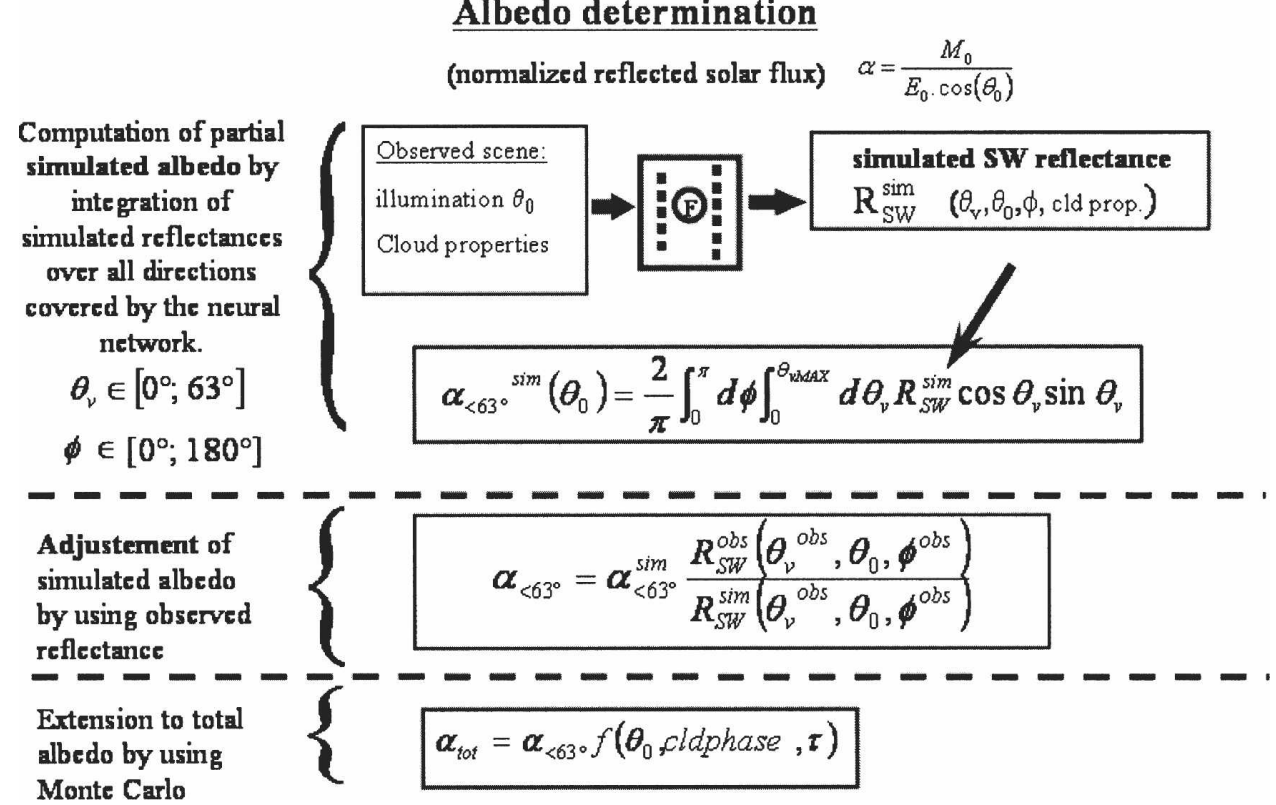

FIG. 4. Scheme of the SW albedo computation.

radiances. The performance of these ADMs is presented in Fig. 1b. The angular dependence of the SW albedo is reduced to about 0.01 and 0.02 for water clouds and for ice clouds, respectively. We will see in section 4 (Fig. 9) that the cirrus SW albedo derived using these ADMs is in general closer to the simulations than the one derived using ERBE ADMs.

\section{d. Collocation of TOVS and ScaRaB-ISCCP data}

The ScaRaB-ISCCP daytime dataset has been collocated with quasi-simultaneous $(\Delta t<30 \mathrm{~min})$ large-scale semitransparent cirrus TOVS data from NOAA-11 and $N O A A-12$ satellite observations. To ensure large-scale cirrus, each of the original ISCCP pixels within a grid of $1^{\circ}$ latitude $\times 1^{\circ}$ longitude has to be cloudy. Furthermore, the optical thickness determined on the ScaRaB pixels has to be larger than 0.7 . This leads to 4130 cases for the period from March 1994 until August 1994: 1570 cases over land and 2560 cases over ocean. Here, $\theta_{0}$ lies between $50^{\circ}$ and $70^{\circ}$ and $\phi$ is less than $40^{\circ}$ (forward scattering) or larger than $140^{\circ}$ (backward scattering).

\section{e. Selection of single-layer cirrus cases}

Passive remote sensing does not give information on the vertical structure of clouds. TOVS Path-B provides only properties of the uppermost cloud. However, for the analysis of the effect of cirrus microphysical properties on radiation, we have to be sure to compare simulated and retrieved fluxes for single cirrus layers. For the case of thin cirrus with an underlying water cloud, it was shown in (Stubenrauch et al. 1999b) that the effective IR emissivity computed from the VIS reflectance is larger than the retrieved $\varepsilon_{\text {cld }}$ of TOVS Path-B. This is because the IR sounder-derived cloud properties are dominated by the properties of the uppermost cloud, whereas the VIS reflectance of thin cirrus is small and hence is dominated by the lower cloud layer. The contrast decreases with increasing $\varepsilon_{\text {cld }}$. Based on this result, the difference between the effective IR emissivity from the VIS reflectance and $\varepsilon_{\text {cld }}$ can be used to distinguish between single and multilayer cirrus when the upperlevel cirrus is optically thin $\left(\varepsilon_{\text {cld }}<0.5\right)$. For thick cirrus, the method breaks down since the VIS reflectance is insensitive to the underlying cloud. This limitation should have little effect on TOA flux since it is insensitive to the lower cloud layer when the upper layer is optically thick.

For the detection of multilayer clouds, the ScaRaB VIS reflectance is first converted into a cloud VIS albedo by applying VIS ADMs, as in Eq. (2), and then transformed into a VIS albedo normalized to a sun at zenith $\alpha_{\mathrm{VIS}}\left(\theta_{0}=0^{\circ}\right)$ from which one computes VIS optical thickness $\tau$. For ice clouds the latter can be linked to IR emissivity $\varepsilon_{\mathrm{IR}}$ as in (Minnis et al. 1993) by

$$
\varepsilon_{\mathrm{IR}}(\tau)=1-\exp (-\tau / 2.13) .
$$

The VIS ADMs have been determined from Monte Carlo simulations using irregular polycrystals (Schlimme et al. 2005), averaged between $\phi<40^{\circ}$ and $\phi>140^{\circ}$ (the range of the collocated observations), and then have been parameterized as a function of $\theta_{v}$, separately 
TABLE 2. Regression coefficients, in Eq. (4), to determine cirrus ADMs as a function of $\theta_{v}$, for two different $\theta_{0}$.

\begin{tabular}{cccccccc}
\hline \hline$\tau$ & $c_{1}$ & $c_{2}$ & $c_{3}$ & $c_{4}$ & $c_{5}$ & $c_{6}$ & $c_{7}$ \\
\hline \multicolumn{7}{c}{$\theta_{0}=51^{\circ}$} \\
1.1 & 0.671 & 2.027 & 0.068 & 32.500 & 0.126 & 0.222 & 1.230 \\
4.6 & 0.817 & 2.104 & 0.064 & 10.100 & 0.181 & 14.640 & 0.176 \\
& \multicolumn{7}{c}{$\theta_{0}=69^{\circ}$} \\
1.1 & 0.595 & 2.469 & 0.101 & 29.700 & 0.143 & 0.279 & 1.142 \\
4.6 & 0.752 & 2.246 & 0.091 & 25.100 & 0.131 & 0.307 & 0.821 \\
\hline
\end{tabular}

for two types of cirrus $(\tau=1.1$ and $\tau=4.6)$ and two $\theta_{0}$ $\left(51^{\circ}\right.$ and $\left.69^{\circ}\right)$ :

$$
\begin{aligned}
R_{\mathrm{VIS}}\left(\theta_{v}\right)= & c_{1}+c_{2} \sin \left(c_{3} \theta_{v}\right)+c_{4} \sin ^{2}\left(c_{5} \theta_{v}\right) \\
& +c_{6} \sin ^{3}\left(c_{7} \theta_{v}\right)
\end{aligned}
$$

the seven coefficients in (7) are listed in Table 2.

The VIS ADMs and the ratio $\alpha_{\mathrm{VIS}}\left(\theta_{0}=0^{\circ}\right) / \alpha_{\mathrm{VIS}}\left(\theta_{0}\right)$, obtained from the same Monte Carlo observations, are presented in Fig. 5 as functions of $\theta_{v}$ and $\theta_{0}$, respectively. Cloud VIS optical thickness is then computed as in Fig. 4.7 of (Rossow et al. 1996) by

$$
\begin{array}{r}
\tau=4.5 \exp \left[1.463 \ln \left(2 \alpha_{\mathrm{VIS}}\right)\right] \quad \text { for } \quad \alpha_{\mathrm{VIS}}<0.505 \\
\tau=4.5 \exp \left[-1.463 \ln \left(2-2 \alpha_{\mathrm{VIS}}\right)\right] \\
\text { for } \quad \alpha_{\mathrm{VIS}} \geq 0.505 .
\end{array}
$$

Using ice crystals of the shape of hexagonal columns, the ADMs are slightly steeper but, since these ADMs are only used in the process of selecting single-layer cirrus clouds, the effect on the final SW albedos is negligible. To illustrate the effect of multilayer clouds, distributions of the difference $\left[\varepsilon_{\mathrm{IR}}(\tau)-\varepsilon_{\mathrm{cld}}\right]$ are shown in Fig. 6, separately for optically thick $\left(\varepsilon_{\text {cld }}>0.75\right)$ and optically thin $\left(0.3<\varepsilon_{\text {cld }}<0.5\right)$ cirrus, 1$)$ before application of the VIS ADMs and 2) after application of the VIS ADMs. For thin cirrus one observes indeed a tail of the distribution toward larger positive values, indicating cases of multilayer clouds. After application of the VIS ADMs the distributions are better centered around 0 . However, one observes that there are also few cases with $\varepsilon_{\mathrm{IR}}(\tau)-\varepsilon_{\text {cld }}<-0.2$. A further investigation showed that for these cases the ScaRaB VIS optical thickness is smaller than the HIRS VIS optical thickness, meaning probably that within the allowed 30 min of observation time difference between HIRS and ScaRaB the observed scenes are not the same. To use only cases with consistent $\varepsilon_{\text {cld }}$ and $\varepsilon_{\mathrm{IR}}(\tau)$, we keep for the following analysis only cases with $\left|\varepsilon_{\mathrm{IR}}(\tau)-\varepsilon_{\text {cld }}\right|<$ 0.2 , in total about 1600 single-layer optically thin cirrus and cirrus over ocean.

\section{The Met Office radiative transfer model}

The radiation code used in the following section to simulate fluxes was developed for use in both forecasting and climate models at the Met Office (Edwards and
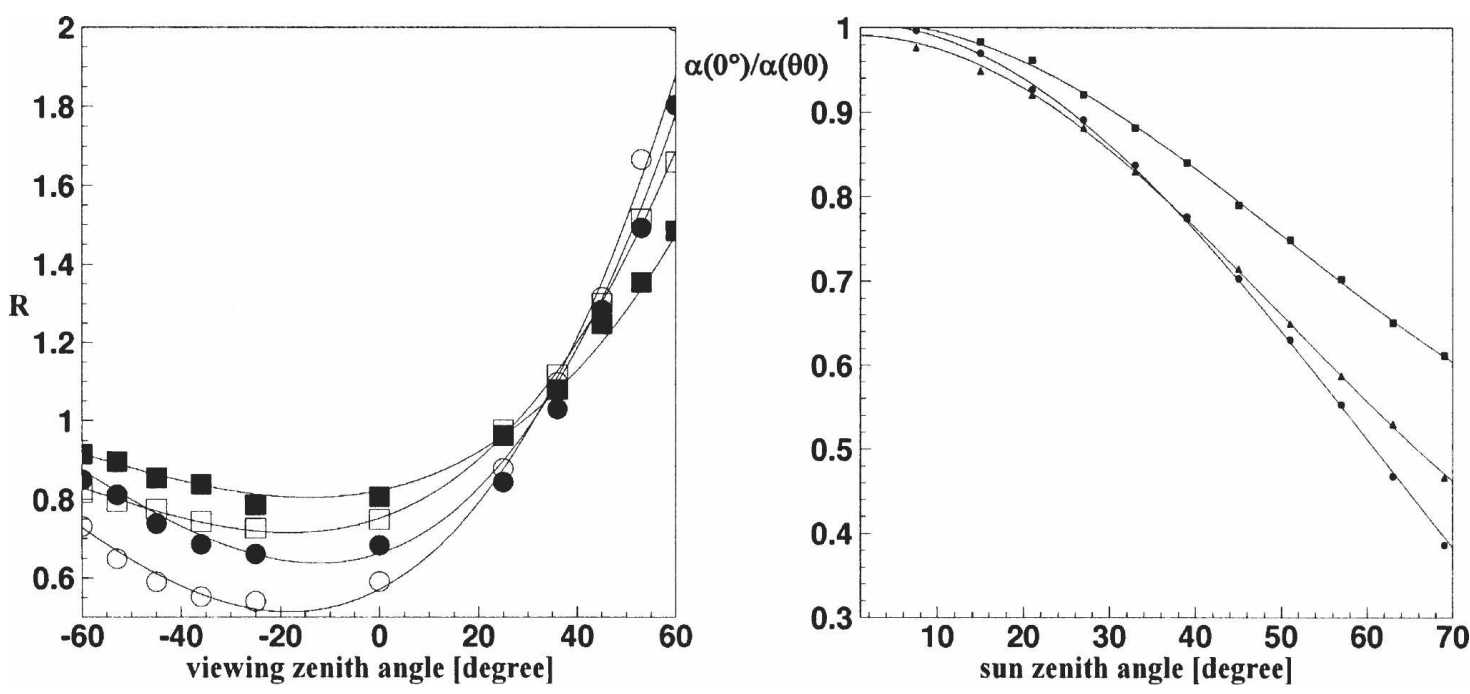

FIG. 5. Angular corrections to be applied for the computation of cloud optical thickness, from Monte Carlo simulations of cirrus consisting of ice aggregates, averaged for $\phi<40^{\circ}$ and $\phi>140^{\circ}$ : (left) VIS ADMs as a function of viewing zenith angle (negative angles correspond to backscattering) for two types of cirrus and two sun zenith angles: $\theta_{0}=51^{\circ}: \tau=1.1$ $(\bullet), \tau=4.6(\square) ; \theta_{0}=69^{\circ}: \tau=1.1(\bigcirc), \tau=4.6(\square)$; (right) fraction of VIS albedo at zenith as function of sun zenith angle for cirrus with $\tau=1.1(\bullet), \tau=2.6(\boldsymbol{\Delta})$, and $\tau=4.6(\bullet)$. 

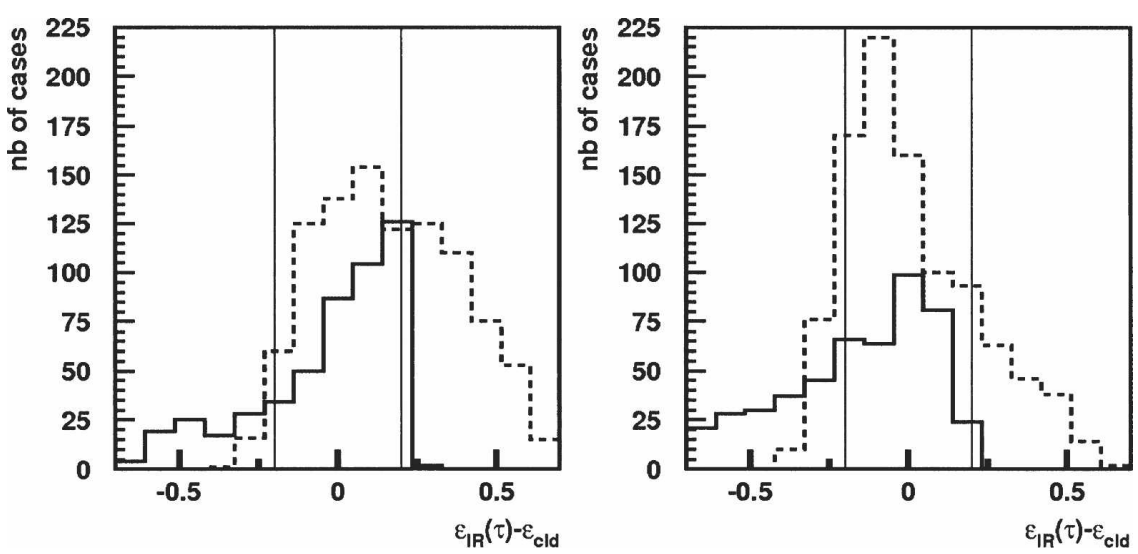

FIG. 6. Distributions of the difference between cloud effective emissivity obtained from visible optical thickness and IR effective emissivity, separately for optically thick $\left(\varepsilon_{\mathrm{IR}}>0.75\right.$ : solid line) and optically thin $\left(0.3<\varepsilon_{\mathrm{IR}}<0.5\right.$ : dashed line) cirrus (a) before application and (b) after application of VIS ADMs.

Slingo 1996). An important consideration in the design of this code was flexibility to allow the use of different spectral configurations and parameterizations.

\section{a. Flux computations}

Radiative fluxes are computed by choosing appropriate two-stream approximations for the spectral region. For the analysis in section 4 the Eddington approximation is used with delta rescaling to calculate forward and backward scattering in the SW and an approximation of Zdunkowski et al. (1980) in the LW. The spectral flexibility of the code comes from the use of a precalculated database containing all spectrally dependent information necessary to solve the radiative transfer equations. In this study, 25 spectral bands are used in the solar part and 12 in the thermal part, as dictated by the spectral resolution of the available parameterizations of the single-scattering properties (extinction coefficient, asymmetry factor, and single scattering albedo) of ice crystals: the limits of these bands are shown in Table 3. Gas absorption is computed in each of these spectral bands using the correlated- $k$ techniques $(\mathrm{Cu}-$ sack et al. 1999).

\section{b. Parameterizations of single scattering properties of ice crystal distributions in cirrus}

The single scattering properties, mass extinction coefficient $\beta_{\text {ext }}$, single scattering albedo $\omega_{0}$, and the asymmetry $g$, depend on wavelength as well as on size and shape of the ice crystals. An exact scattering theory for nonspherical particles covering all size parameters (ratio of ice crystal size and radiation wavelength) does not exist. Depending on the size parameter, various numerical approaches have been developed to simulate scattering and absorption by nonspherical cirrus ice particles. In climate models ice crystal single scattering properties are given for different spectral bands, covering the whole range of SW and LW radiation.

In the SW domain the size of the ice crystals is much larger than the wavelength, and therefore the single scattering properties can be determined using the approximation of geometric optics. At the shorter wave-

TABLE 3. Spectral bands of Met Office radiative transfer model used in this analysis.

\begin{tabular}{ccc}
\hline \hline Band & $\begin{array}{c}\text { SW spectral } \\
\text { region }(\mu \mathrm{m})\end{array}$ & $\begin{array}{c}\text { LW spectral } \\
\text { region }(\mu \mathrm{m})\end{array}$ \\
\hline 1 & $0.25-0.30$ & $35.71-1000.00$ \\
2 & $0.30-0.33$ & $25.00-35.71$ \\
3 & $0.33-0.36$ & $18.52-25.00$ \\
4 & $0.36-0.40$ & $14.93-18.52$ \\
5 & $0.40-0.44$ & $12.50-14.93$ \\
6 & $0.44-0.48$ & $10.20-12.50$ \\
7 & $0.48-0.52$ & $9.09-10.20$ \\
8 & $0.52-0.57$ & $8.00-9.09$ \\
9 & $0.57-0.64$ & $7.14-8.00$ \\
10 & $0.64-0.69$ & $5.88-7.14$ \\
11 & $0.69-0.75$ & $5.26-5.88$ \\
12 & $0.75-0.78$ & $4.55-5.26$ \\
13 & $0.78-0.87$ & \\
14 & $0.87-1.00$ & \\
15 & $1.00-1.10$ & \\
16 & $1.10-1.19$ & \\
17 & $1.19-1.41$ & \\
18 & $1.41-1.53$ & \\
19 & $1.53-1.64$ & \\
20 & $1.64-2.13$ & \\
21 & $2.13-2.38$ & \\
22 & $2.38-2.91$ & \\
23 & $2.91-3.42$ & \\
24 & $3.42-4.00$ & \\
25 & $4.00-4.99$ & \\
\hline
\end{tabular}


lengths, extinction happens exclusively through scattering, and therefore the phase function (or the asymmetry) becomes important.

In the LW domain the size parameter approaches one, and absorption becomes important. To describe the absorption in ice crystals several methods have been used: Fu et al. (1998) developed a method based on fitting a combination of Lorenz-Mie and improved geometric optics calculations to finite-difference-timedomain (FDTD) computations. Mitchell et al. (1996) use an improved version of the anomalous diffraction approximation (Van de Hulst 1957). Recently, Baran (2003) calculated single scattering properties of ice crystals by representing them as an ensemble of circular ice cylinders of varying size and shape using the Tmatrix method (Mishchenko 1991) for crystal sizes up to $175 \mu \mathrm{m}$ and the complex angular momentum approximation (Nussenzveig and Wiscombe 1980) for larger crystals.

The Met Office radiative transfer includes three parameterizations, each based on a different one of these approaches in the LW domain (Edwards et al. 2007). Each parameterization has a consistent SW counterpart based on the method of improved geometric optics (Yang and Liou 1996).

The first parameterization assumes hexagonal ice columns (Fu 1996; Fu et al. 1998) integrated over an average size distribution obtained from 28 in situ size distributions collected in the midlatitudes and Tropics. Crystal sizes are expressed in terms of a generalized effective ice crystal dimension $D_{\text {ge }}$. The other two parameterizations treat ice crystal aggregates.

For the SW region, Baran et al. (2001) developed a representation of the single scattering properties of an ensemble of two to eight hexagonal ice columns with roughened surfaces (Yang and Liou 1998), with a phase function based on geometrical optics and the laboratory data of Volkovitskiy et al. (1980). Baran (2003) provided a corresponding scheme for the LW region. These single scattering properties have been integrated over an average size distribution obtained from 54 size distributions collected during the Central Equatorial Pacific Experiment (CEPEX) campaign (McFarquar and Heymsfield 1996) and then parameterized as functions of a mean effective ice crystal dimension $D_{e}(\mathrm{Ed}-$ wards et al. 2007):

$$
\begin{aligned}
D_{e} & =\frac{3}{2} \int_{0}^{\infty} V(D) \frac{d N}{d D} d D / \int_{0}^{\infty} P(D) \frac{d N}{d D} d D \\
& =3 \frac{\sqrt{3}}{4} D_{\mathrm{ge}}
\end{aligned}
$$

where $V$ is the volume of the ice crystal and $P$ its projected area.

The scheme of Mitchell et al. (1996), as parameterized for use in a GCM (Kristjânsson et al. (2000), treats ice crystals as aggregates or hexagonal plates. A bimodal size distribution is assumed and crystal sizes are expressed in terms of the mean maximum dimension of the large mode, $D_{l}$, a variable that is measured in field campaigns. In general, $D_{l}$ is not directly related to $D_{e}$, as is $D_{\text {ge }}$, but for a given size distribution and crystal shape a relationship can be established, enabling all parameterizations to be expressed in terms of $D_{e}$.

In the radiative transfer model the single scattering properties for each scheme in each of the bands listed in Table 3 are expressed as polynomials in the appropriate measure of crystal size $\left(D_{\mathrm{ge}}, D_{l}\right.$, or $\left.D_{e}\right)$. Comparisons of the schemes are given in Edwards et al. (2007).

\section{Cirrus radiative flux analysis}

Given the state of the atmosphere at a particular point, an accurate parameterization should simulate the observed SW and LW fluxes at TOA. In practice, HIRS IR radiance measurements were used to retrieve cloud properties $\left(p_{\mathrm{cld}}\right.$ and $\left.\varepsilon_{\mathrm{cld}}\right)$. This precludes any assessment of the simulation of LW fluxes. However, once the cloud properties have been retrieved, the SW fluxes can be simulated (using $p_{\text {cld }}$ and IWP determined from $\varepsilon_{\text {cld }}$ under a specific assumption of $D_{e}$ ) and compared to the observed values. The consistency between the observed and simulated fluxes can then be used to assess the performance of the various parameterizations.

Specifically, we compare simulated to observed cirrus $\alpha_{\mathrm{SW}}$, the latter linked to IWP and $D_{e}$ by retrieved cirrus IR $\varepsilon_{\text {cld }}$. In section 4 a we first describe the method and present sensitivities of the simulated $\alpha_{\mathrm{SW}}$ to the different assumptions and uncertainties of the input: atmospheric water vapor profiles, geometrical thickness of the cirrus, and SW ADMs. At last the sensitivity of simulated $\alpha_{\mathrm{SW}}$ to $D_{e}$ and to ice crystal habit (pristine or aggregate) is explored. In section $4 b$ these multiple simulations (varying $D_{e}$ for the same retrieved IR $\varepsilon_{\mathrm{cld}}$ for each of the three parameterizations of ice crystal single scattering properties described in section $3 b$ ) of $\alpha_{\mathrm{SW}}$ are compared to observed cirrus $\alpha_{\mathrm{SW}}$ from ScaRaB, and the $D_{e}$ that leads to the best fit of $\alpha_{\mathrm{Sw}}$ to the observation is kept for each case. Then the relation between the fitted $D_{e}$ and IWP that match the IR $\varepsilon_{\text {cld }}$ are studied, leading to a parameterization of $D_{e}$ as a function of IWP. At last a parameterization of $D_{e}$ as a function of cloud temperature, already used in a climate model, is tested by determining $D_{e}$ from TOVS cloud temperature and comparing the simulated $\alpha_{\mathrm{SW}}$ to the observations. 


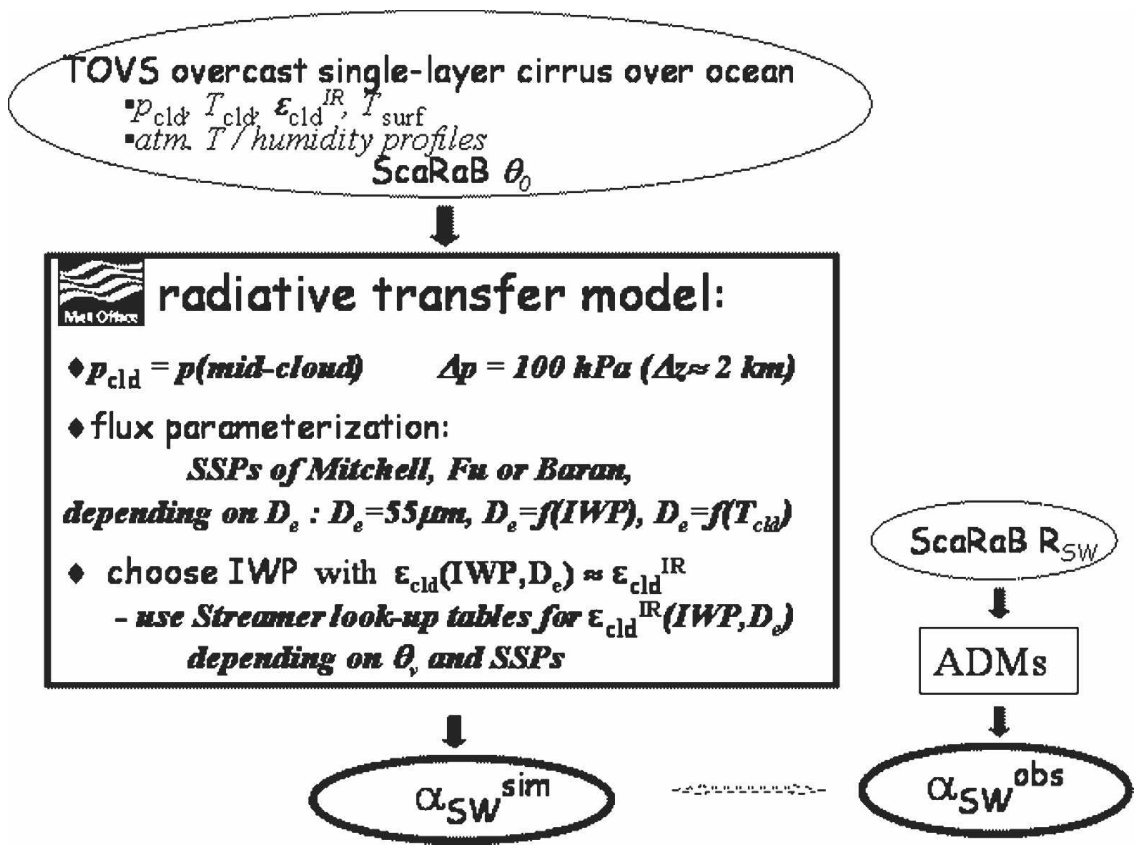

FIG. 7. Scheme of cirrus radiative flux analysis.

\section{a. Method and sensitivity studies}

Figure 7 presents the flux analysis scheme. Atmospheric temperature and humidity profiles for the radiative transfer computation are given as the profiles of the Thermodynamic Initial Guess Retrieval (TIGR) database (Chédin et al. 1985; Chevallier et al. 1998) that best fit the retrieved or first-guess atmospheric profiles from TOVS observations (Scott et al. 1999). This is to assure a coherent treatment for all clouds, because atmospheric profiles can only be retrieved for clear sky and thin clouds $\left(\varepsilon_{\mathrm{cld}}<0.6\right)$. The retrieved water vapor profiles are on average more humid than the TIGR profiles, and a sensitivity study (assuming $D_{e}=55 \mu \mathrm{m}$ and the parameterization of Baran) has shown that the effect on $\alpha_{\mathrm{SW}}$ would be an average increase by only about 0.006 . Ozone profiles are taken from a climatology (McPeters et al. 1984).

The cloud data are incomplete in that they do not include the cloud base. The cloud geometrical thickness is fixed to $100 \mathrm{hPa}(\sim 2 \mathrm{~km})$, which is a reasonable average thickness of high clouds according to (Stubenrauch et al. 2005). Using a geometrical thickness of about $50 \mathrm{hPa}(\sim 1 \mathrm{~km})$ would lead to an average decrease of $\alpha_{\mathrm{SW}}$ by about 0.003 .

The most important quantities in determining the effect of clouds on the radiation at the TOA are $p_{\text {cld }}$, IWP, and $D_{e}: p_{\text {cld }}$ is known from the retrievals, and IWP can be inferred from $\varepsilon_{\text {cld }}$ by using radiative transfer calculations (Key and Schweiger 1998), given a treat- ment of ice optics (described in section $3 b$ ) and a value of $D_{e}$ (Stubenrauch et al. 2004). Thus, for any particular value of $D_{e}$, there exists a unique relationship between $\varepsilon_{\text {cld }}$ and IWP for each parameterization of ice crystal single scattering properties. By varying $D_{e}$, the same retrieved $\varepsilon_{\text {cld }}$ leads to different values of IWP. As an example, Fig. 8 presents IWP as a function of $\varepsilon_{\text {cld }}$ separately for ice crystal single scattering parameterizations of Fu and Baran for small $\left(D_{e}=20 \mu \mathrm{m}\right)$ and large

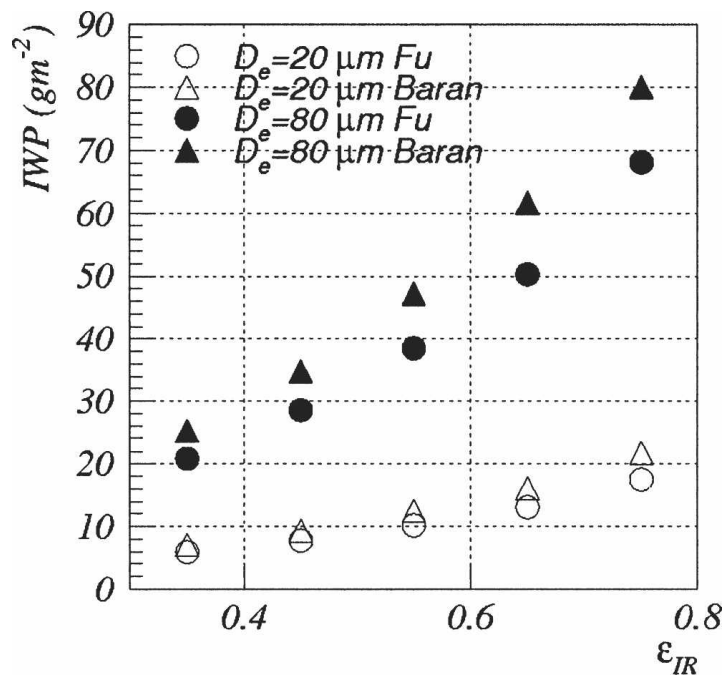

FIG. 8. Cirrus IWP determined from retrieved $\varepsilon_{\text {cld }}$ for different assumptions of $D_{e}$ and single scattering property parameterizations. 

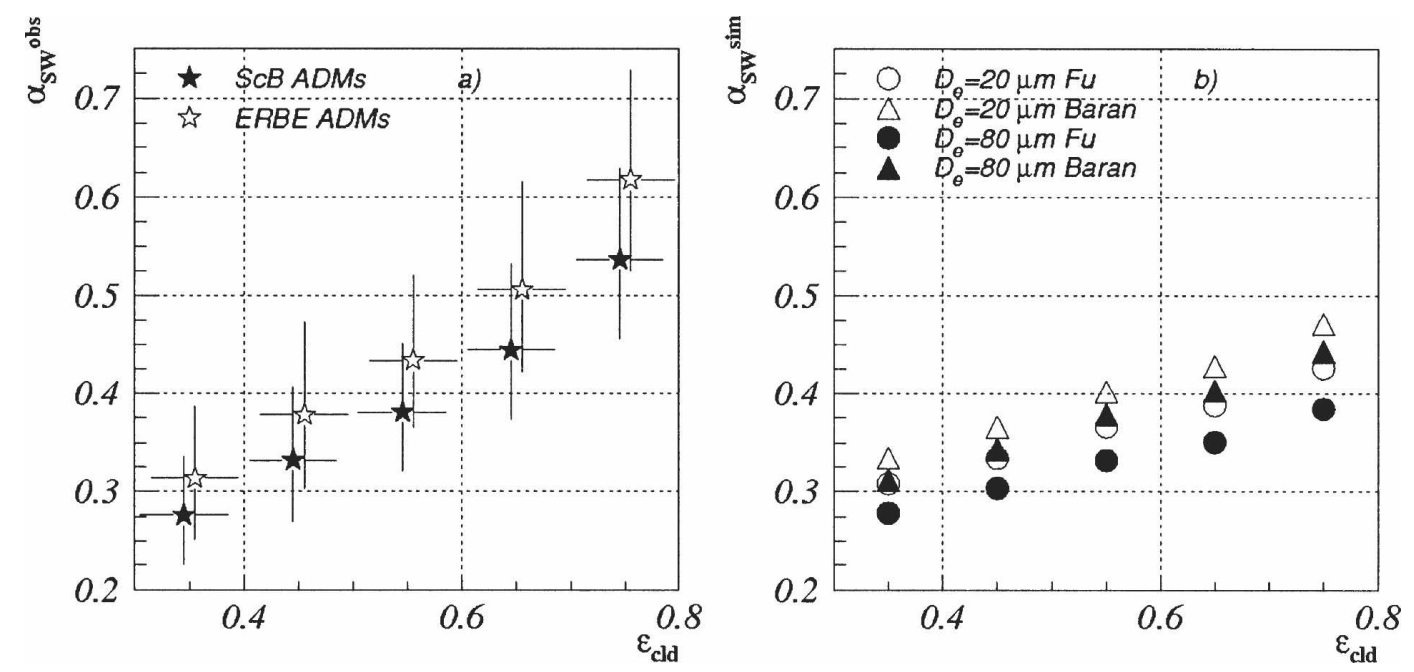

FIG. 9. (a) Observed cirrus SW albedo (from ScaRaB) as function of observed $\varepsilon_{\text {cld }}$ (from TOVS) for all observations. Compared are $\alpha_{\mathrm{SW}}^{\mathrm{obs}}$ obtained using the ERBE ADMs and using the ADMs developed by Briand (2000), described in this article. (b) Simulated cirrus SW albedo $\alpha_{\mathrm{SW}}^{\mathrm{sim}}$ as a function of observed $\varepsilon_{\mathrm{cld}}$, for two different single scattering property parameterizations and for two fixed $D_{e}$.

$\left(D_{e}=80 \mu \mathrm{m}\right)$ ice crystals. For the same $\varepsilon_{\text {cld }}$ IWP increases with $D_{e}$, and the increase is much larger at large $\varepsilon_{\text {cld. }}$. Figure 8 also shows that the effect of ice crystal shape on IWP is smaller than the effect of $D_{e}$. Nevertheless the IWP is about $20 \%$ smaller for pristine ice crystal shapes than for aggregates for large ice crystals. For smaller crystals the effect becomes visible only for $\varepsilon_{\text {cld }}>0.5$. The IWP is computed from $\varepsilon_{\text {cld }}$ by using lookup tables described above, depending on $\varepsilon_{\text {cld }}$ and $D_{e}$.

The single scattering properties used in the radiative transfer computations come from the same parameterization scheme (see section $3 b$ ) as in the simulation of $\alpha_{\mathrm{SW}}$, assuming a pristine ice crystal shape $(\mathrm{Fu})$, or aggregates using different representations (Mitchell and Baran). Having retrieved the IWPs corresponding to a range of values of $D_{e}$ (from 10 to $90 \mu \mathrm{m}$ in steps of 10 $\mu \mathrm{m}$, together with the value of $55 \mu \mathrm{m}$ ), the SW albedos are simulated for each of these pairs of $D_{e}$ and IWP and these simulated values are compared with the observed albedos from ScaRaB.

The elimination of multilayer clouds and of cases for which effective emissivity retrieved from VIS reflectance and from HIRS do not agree (see section 2e) increases the general agreement between simulated and observed SW albedos from $54 \%-74 \%$ within \pm 0.10 . An underestimation of $\varepsilon_{\text {cld }}$ by 0.05 would lead to an average underestimation of $\alpha_{\mathrm{SW}}$ by about 0.015 (again assuming $D_{e}=55 \mu \mathrm{m}$ and the parameterization of Baran).

As $\varepsilon_{\text {cld }}$ is closely related to the emitted LW flux at TOA, this procedure effectively constrains the calculated LW flux to be consistent with the observed value.
By using the cirrus effective IR emissivity to predict the reflected SW flux the measure of agreement found between the observed and calculated SW fluxes provides a measure of the reliability of the parameterization.

Before the specific analysis in section $4 \mathrm{~b}$ we show in Fig. 9a how the effective IR cirrus emissivity from TOVS and the corresponding cirrus $\alpha_{\mathrm{SW}}$ from ScaRaB are correlated, using separately ERBE ADMs and ScaRaB ADMs (see section 2b) to determine $\alpha_{\mathrm{SW}}^{\mathrm{obs}}$. For each of the five $\varepsilon_{\text {cld }}$ intervals, the average and the width of the distribution of $\alpha_{\mathrm{SW}}^{\mathrm{obs}}$ are presented, the latter by asymmetric error bars. Average $\alpha_{\mathrm{SW}}^{\mathrm{obs}}$ increases with IR $\varepsilon_{\text {cld }}$. It is systematically lower when using the ScaRaB ADMs, and the widths of the distributions are also slightly smaller in this case. Figure $9 \mathrm{~b}$ presents simulations of $\alpha_{\mathrm{SW}}$, also as a function of $\varepsilon_{\text {cld }}$. Compared are results using the parameterizations of $\mathrm{Fu}$ and Baran, each assuming $D_{e}=20 \mu \mathrm{m}$ and $D_{e}=80 \mu \mathrm{m}$. One first observes that the slope of $\alpha_{\mathrm{SW}}^{\mathrm{obs}}$ in dependence of $\varepsilon_{\mathrm{cld}}$ could be more easily reconstructed from the simulations when using the ScaRaB ADMs instead of the ERBE ADMs. From Fig. 9 one can also deduce that the simulations would fit the observations best if $D_{e}$ is not constant, but if it decreases with $\varepsilon_{\text {cld }}$. For each IR $\varepsilon_{\text {cld }}$ different pairs of IWP and $D_{e}$ are possible, and in the following we will determine for each data point which of the pairs would give the $\alpha_{\mathrm{SW}}$ that best fits the ScaRaB observations.

Since IWP and $D_{e}$ are the relevant variables to determine $\alpha_{\mathrm{SW}}$ in climate models, we determine in the next section the $D_{e}$ and the parameterization that fit the databest, in dependence of IWP. We also test the sen- 

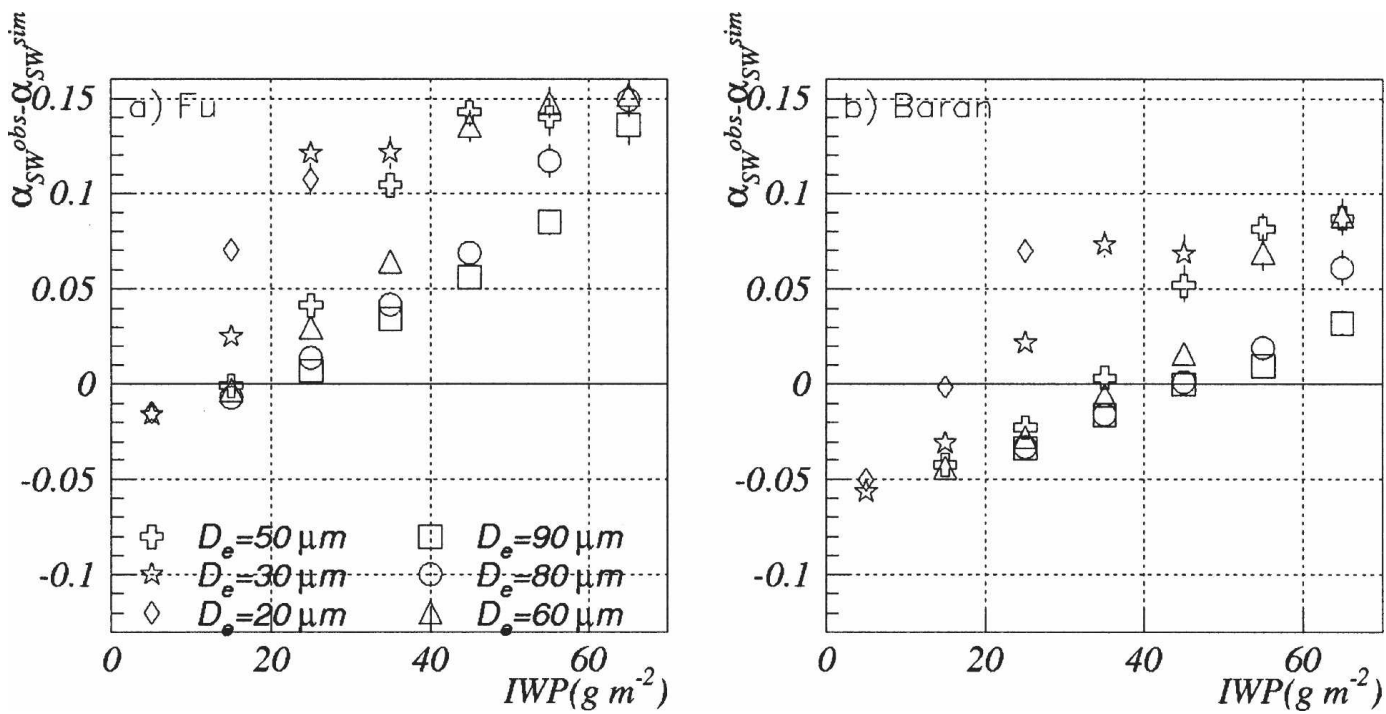

FIG. 10. Difference between the observed and simulated single-layer cirrus SW albedo as a function of the cirrus IWP. Simulations carried out varying $D_{e}$ between 20 and $90 \mu \mathrm{m}$ and using (a) the parameterization of Fu for ice crystals with the shape of hexagonal columns and (b) the parameterization of Baran for ice crystal aggregates.

sitivity of $\alpha_{\mathrm{SW}}$ to the assumed behavior of $D_{e}$ : being constant, increasing with IWP, and increasing with cloud temperature.

For each of the three parameterizations described in section 3, nine SW albedos have been simulated from the properties of the 1560 cirrus by varying $D_{e}$ from 10 to $90 \mu \mathrm{m}$ in steps of $10 \mu \mathrm{m}$. Figure 10 presents the average differences between $\alpha_{\mathrm{SW}}^{\mathrm{obs}}-\alpha_{\mathrm{SW}}^{\mathrm{sim}}$ for seven intervals of retrieved IWP between 0 and $70 \mathrm{~g} \mathrm{~m}^{-2}$. Results are shown for six assumptions about $\left.D_{e}, 1\right)$ for the parameterization of $\mathrm{Fu}$ and 2) for the parameterization of Baran. Note that for each observed $\varepsilon_{\text {cld }}$ the simulations are distributed in different IWP intervals, depending on the assumed $D_{e}$, and in general there are less than six difference values in each of the IWP intervals physically possible, especially at small and large IWP. First one observes, as already suggested from Fig. 9, that the simulations fit the data best if one chooses a $D_{e}$ that increases with IWP. From Fig. 10 one also can deduce that for IWP $>30 \mathrm{~g} \mathrm{~m}^{-2}, \alpha_{\mathrm{SW}}^{\mathrm{obs}}$ cannot be reproduced from the observed IR $\varepsilon_{\text {cld }}$ by a parameterization assuming randomly oriented pristine ice crystals. In this case the average mismatch would be up to 0.15 for IWP between 60 and $70 \mathrm{~g} \mathrm{~m}^{-2}$. Note also in Fig. 10 that the average of $\alpha_{\mathrm{SW}}^{\mathrm{obs}}-\alpha_{\mathrm{SW}}^{\mathrm{sim}}$ can vary by up to 0.10 , depending on $D_{e}$ alone. This is more than has been shown for $\alpha_{\mathrm{SW}}^{\text {sim }}$ in Fig. $9 \mathrm{~b}$ as function of IR $\varepsilon_{\text {cld }}$. This can be explained that, linking the IR and SW variables by pairs of IWP and $D_{e}$, the differences in the simulations are enhanced.

\section{b. Best-suited parameterizations of $D_{e}$ for climate model simulations}

For each cirrus case $D_{e}$ that fits best the observed $\alpha_{\mathrm{SW}}$ is determined as a weighted average $\left\langle D_{e}\right\rangle_{\mathrm{obs}}$, with weights corresponding to the squared inverse of the difference between observed and simulated $\alpha_{\mathrm{SW}}$, as

$$
\left\langle D_{e}\right\rangle_{\mathrm{obs}}=\sum_{i=1}^{9} \frac{D_{e}^{i}}{\left[\alpha_{\mathrm{SWobs}}-\alpha_{\mathrm{SWsim}}\left(D_{e}^{i}\right)\right]^{2}} / \sum_{i=1}^{9} \frac{1}{\left[\alpha_{\mathrm{SWobs}}-\alpha_{\mathrm{SWsim}}\left(D_{e}^{i}\right)\right]^{2}},
$$

with $D_{e}^{i}=\{10 \mu \mathrm{m}, 20 \mu \mathrm{m}, \ldots, 90 \mu \mathrm{m}\}$

For a specific ice crystal single scattering parameterization the retrieved IR $\varepsilon_{\text {cld }}$ leads then to the corresponding $\langle\mathrm{IWP}\rangle_{\text {obs }}$.

Figure 11a presents $\left\langle D_{e}\right\rangle_{\text {obs }}$ as a function of $\langle\mathrm{IWP}\rangle_{\text {obs }}$ for the single scattering property parameterizations of Baran, Mitchell, and Fu. For all ice crystal shape as- sumptions $D_{e}$ fits best the observations if it increases with IWP:

$$
\begin{aligned}
D_{e}= & -39.072+44.025 \ln (\mathrm{IWP})-5.004[\ln (\mathrm{IWP})]^{2} \\
& \text { for } 70 \mathrm{~g} \mathrm{~m}^{-2}>\mathrm{IWP}>3 \mathrm{~g} \mathrm{~m}^{-2},
\end{aligned}
$$

with $D_{e}=3 \mu \mathrm{m}$ for IWP $<3 \mathrm{~g} \mathrm{~m}^{-2}$. 

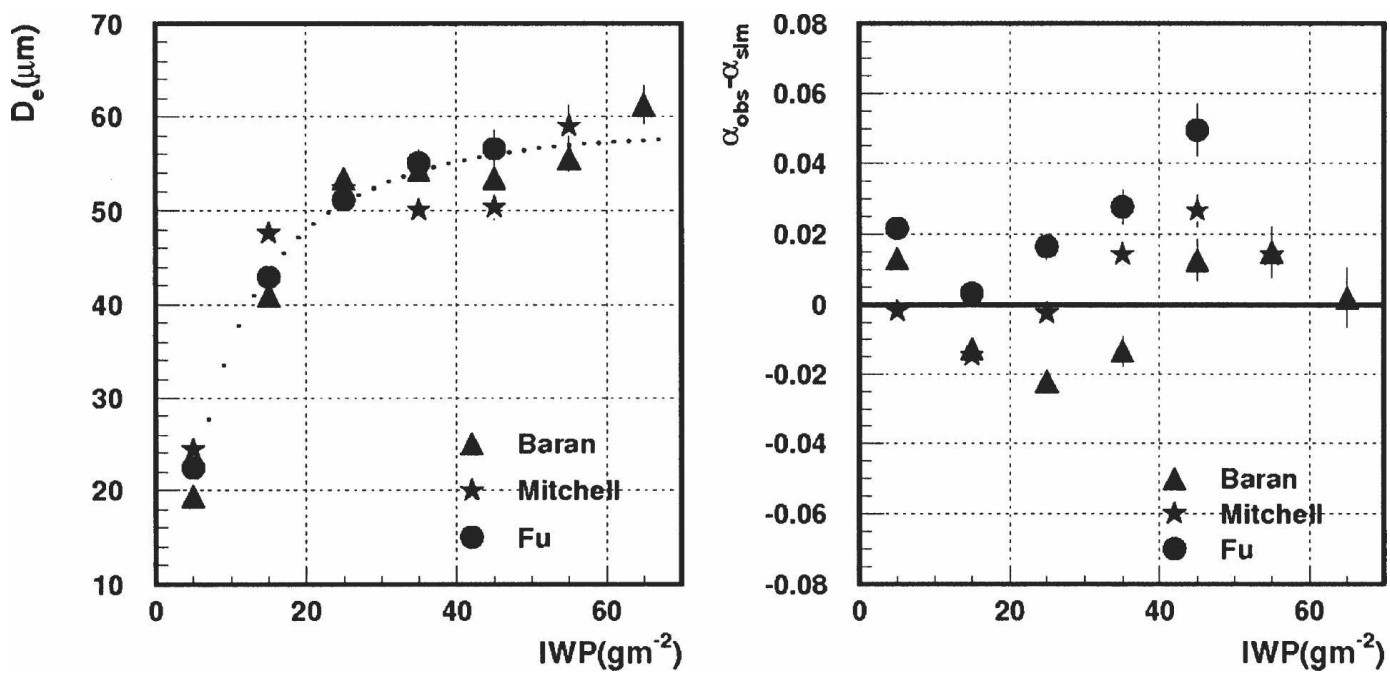

FIG. 11. (a) Plot of $\left\langle D_{e}\right\rangle_{\text {obs }}$ as a function of $\langle\mathrm{IWP}\rangle_{\text {obs }}$ for the three single scattering parameterizations. The dotted curve corresponds to the fitted function of Eq. (9). (b) The difference between observed and simulated cirrus SW albedo, using $\left\langle D_{e}\right\rangle_{\text {obs }}$, as a function of $\langle\mathrm{IWP}\rangle_{\text {obs }}$.

One would need a satellite mission operating at submillimeter wavelengths (Buehler et al. 2007, manuscript submitted to Quart. J. Roy. Meteor. Soc.) to study the continuation of the relationship toward larger IWP. Note that a similar behavior of $D_{e}$ with IWP has already been observed for specific regions by Heymsfield (1977), Heymsfield and Platt (1984), and Korolev et al. (2001). The average differences $\alpha_{\mathrm{SW}}^{\mathrm{obs}}-\alpha_{\mathrm{SW}}^{\mathrm{sim}}$ for $\left\langle D_{e}\right\rangle_{\mathrm{obs}}$, using the three parameterizations, are shown as functions of IWP in Fig. 11b. They lie within \pm 0.025 for both aggregate parameterizations, whereas the param- eterization of Fu leads to cirrus SW albedos that are too small by more than 0.025 for IWP $>30 \mathrm{~g} \mathrm{~m}^{-2}$.

The resulting IWP and $D_{e}$ distributions of these cirrus clouds are presented separately in Fig. 12 for the three parameterizations. Mean values lie between 21 and $32 \mathrm{~g} \mathrm{~m}^{-2}$ and between 45 and $50 \mu \mathrm{m}$, respectively. The smaller values correspond to the assumption of pristine crystals, the largest to the one of aggregates.

In the following we estimate the effect of $D_{e}$ for $\alpha_{\mathrm{SW}}$ determination in climate models. To determine the best-suited $D_{e}$ for cirrus radiative flux computations,
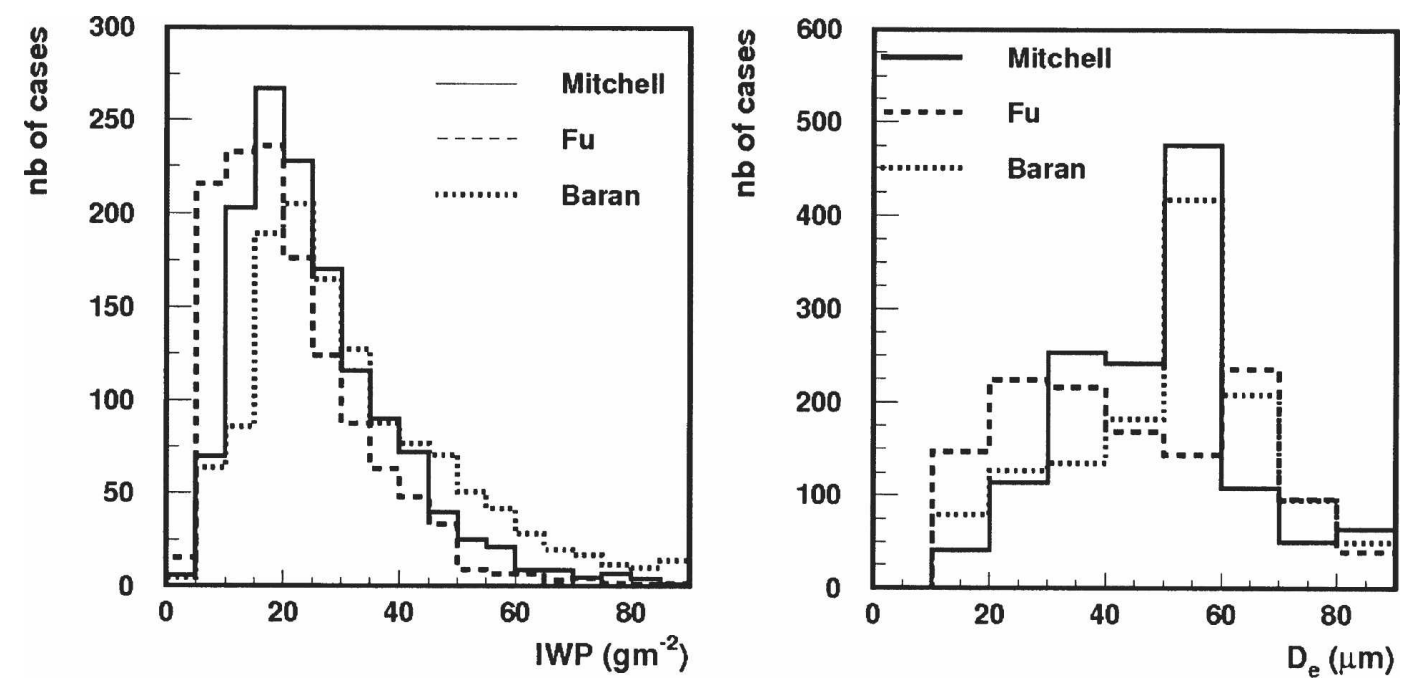

FIG. 12. Distributions of (left) IWP and (right) $D_{e}$ that fit best the $\alpha_{\mathrm{SW}}$ and IR $\varepsilon_{\mathrm{cld}}$ observations, separately for the ice crystal single scattering parameterizations of Baran, Mitchell, and Fu. 

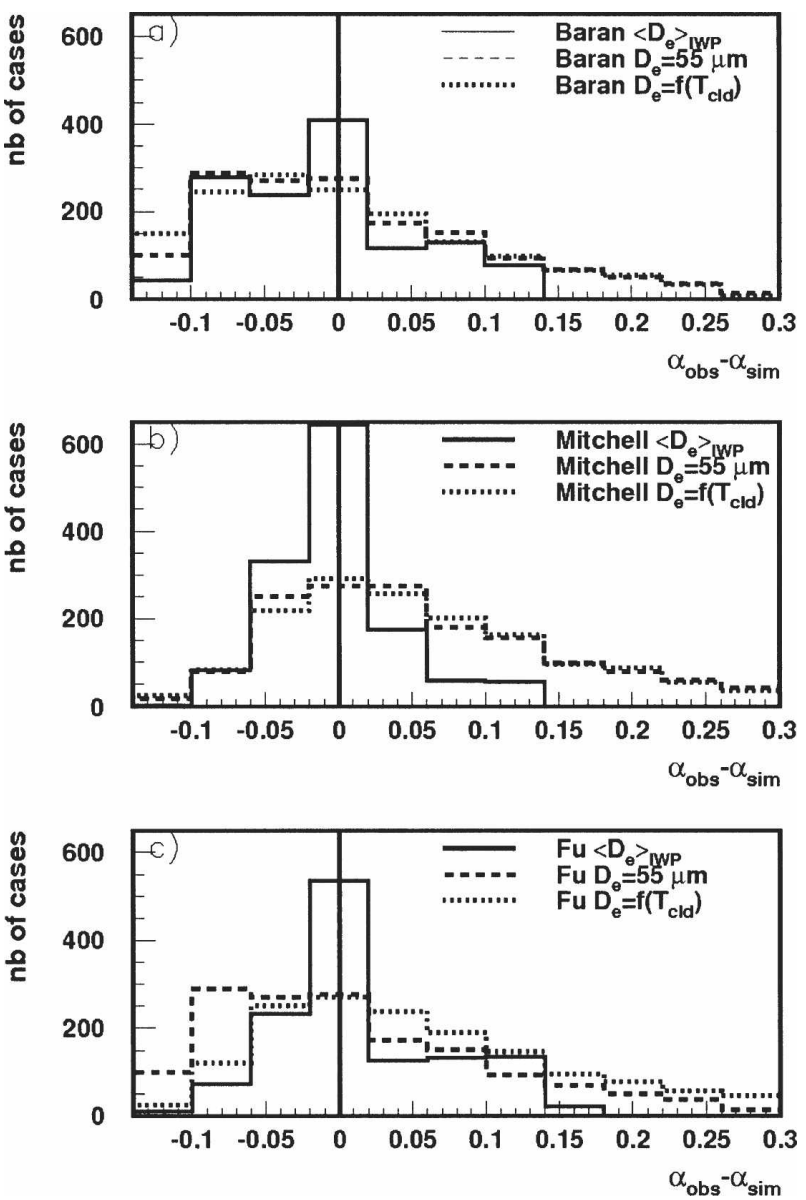

FIG. 13. Distributions of differences between observed and simulated cirrus SW albedo assuming $D_{e}$ increasing with IWP, constant $D_{e}$, and $D_{e}$ increasing with cloud temperature; simulations use the three parameterizations of (a) Baran, (b) Mitchell, and (c) Fu.

distributions of $\alpha_{\mathrm{SW}}^{\mathrm{obs}}-\alpha_{\mathrm{SW}}^{\mathrm{sim}}$ are compared for the three ice crystal single scattering parameterizations, using each time three options for $D_{e}$ :

1) $D_{e}$ increasing with IWP as in Eq. (11),

2) constant $D_{e}$ of $55 \mu \mathrm{m}$, and

3) $D_{e}$ increasing with $T_{\text {cld }}$ as in the Met Office climate model (Edwards et al. 2007):

$$
\begin{aligned}
D_{e}= & 975.51 \mu \mathrm{m} \times \exp \left[0.05 \mathrm{~K}^{-1} \times\left(T_{\mathrm{cld}}-279.5 \mathrm{~K}\right)\right] \\
& +0.66 \mu \mathrm{m} \quad \text { for } \quad T_{\mathrm{cld}} \leq 216.21 \mathrm{~K} \\
D_{e}= & 175.44 \mu \mathrm{m} \times \exp \left[0.05 \mathrm{~K}^{-1} \times\left(T_{\text {cld }}-279.5 \mathrm{~K}\right)\right] \\
& +34.45 \mu \mathrm{m} \quad \text { for } \quad T_{\text {cld }}>216.21 \mathrm{~K} .
\end{aligned}
$$

For option 1, all distributions in Figs. 13 have a large peak centered around 0 with a rms of 0.06, 0.04, and 0.06 respectively for the ice crystal single scattering parameterizations of Baran, Mitchell, and Fu.
However, both other options for $D_{e}$ lead to much broader distributions. Note that the distributions for options 2 and 3 are very similar. This is probably because $T_{\text {cld }}$ varies less for all large-scale single-layer cirrus than the temperature, which is vertically distributed within the cirrus for which the parameterization of Eq. (11) was established using in situ measurements.

We conclude that flux computations for large-scale semitransparent cirrus clouds are more realistic if $D_{e}$ increases with IWP, assuming pristine ice crystal shapes for IWP $<25 \mathrm{~g} \mathrm{~m}^{-2}$ and aggregates for larger IWP. Figure 14 illustrates the differences in $\alpha_{\mathrm{SW}}$ and in $\varepsilon_{\mathrm{IR}}$ for these different assumptions as a function of IWP. The most plausible SW albedos, as from the preceding analyses $\left(D_{e}\right.$ increasing with IWP and pristine crystals/ aggregates for small/large IWP), would be $0.32,0.33$, 0.36 , and 0.4 up to 0.45 for cirrus with IWP $=5,15,25$, 35 , and $55 \mathrm{~g} \mathrm{~m}^{-2}$, respectively. At the same time the cirrus IR emissivity would be $0.41,0.47,0.54,0.56,0.66$, and 0.72 . Compared to the other tested assumptions $\alpha_{\mathrm{SW}}$ is about 0.01 higher, corresponding to a higher reflected SW flux of about $4 \mathrm{~W} \mathrm{~m}^{-2}$ (assuming a global annual mean solar flux of about $342 \mathrm{~W} \mathrm{~m}^{-2}$ ). At smaller IWP constant $D_{e}$ would also lead to an underestimation of about $7 \mathrm{~W} \mathrm{~m}^{-2}$, whereas aggregates lead to a $5 \mathrm{~W}$ $\mathrm{m}^{-2}$ higher reflected SW flux. Choosing small $D_{e}$ and pristine crystals at smaller IWP leads at the same time to IR emissivities larger by more than 0.1 at small IWP. In summary, choosing pristine crystals and small $D_{e}$ at small IWP and aggregates and larger $D_{e}$ at larger IWP leads to a stronger cooling effect of thin cirrus, by increasing both $\alpha_{\mathrm{SW}}$ and $\varepsilon_{\mathrm{IR}}$, whereas for larger IWP a slight increase of the cooling effect is expected only due to an increase of $\alpha_{\mathrm{SW}}$.

\section{Conclusions}

Combined simultaneous satellite observations have been used to evaluate the performance of parameterizations of the microphysical and optical properties of cirrus clouds used for radiative flux computations in climate models. Atmospheric and cirrus properties were retrieved from TOVS satellite observations in the IR using different parameterizations of effective ice crystal size. SW albedos were then simulated with the radiation code in the forecasting and climate model of the Met Office and compared with those retrieved from simultaneous ScaRaB observations of large-scale semitransparent single layer cirrus clouds over ocean. For the retrieval of SW albedos, newly developed ADMs, depending on cloud phase, optical thickness, and IR heterogeneity were used in place of ERBE ADMs: these reduced the retrieved SW albedo of these cirrus 

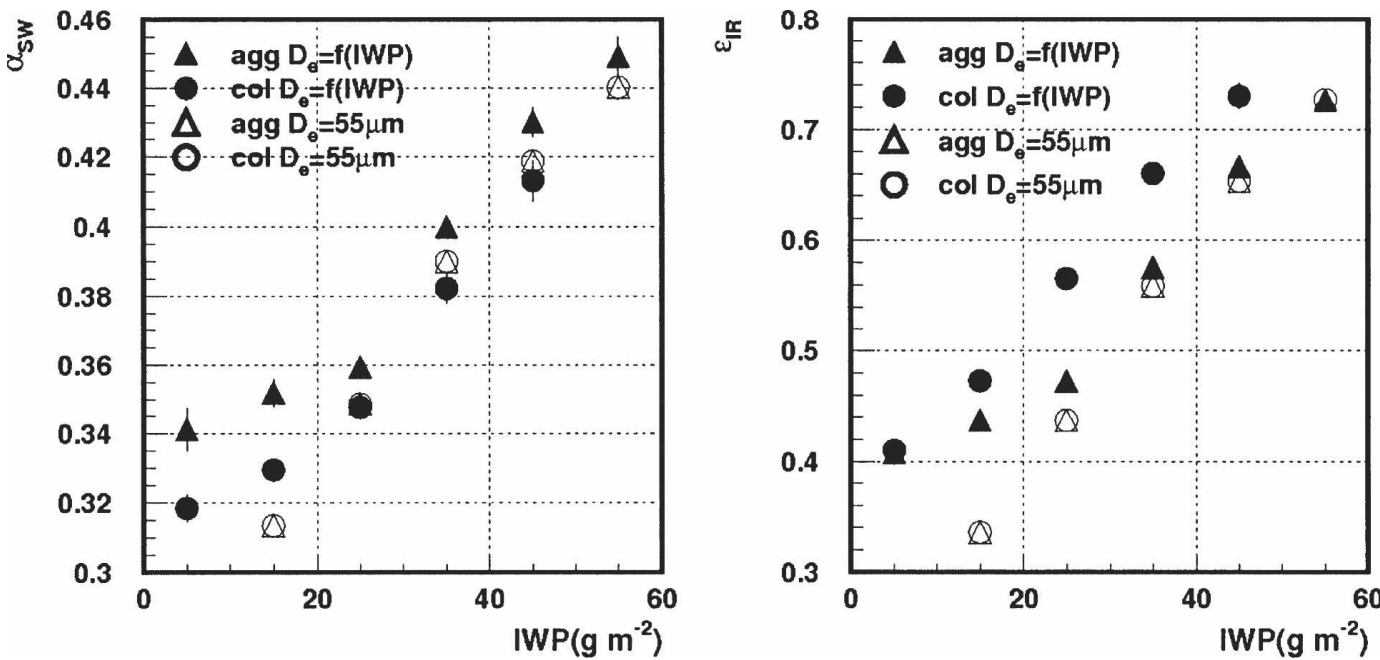

FIG. 14. (a) Cirrus SW albedo as a function of IWP assuming constant $D_{e}$ and $D_{e}$ increasing with IWP for ice crystals treated as hexagonal columns and as aggregates. Solar zenith angles lie between $50^{\circ}$ and $70^{\circ}$. (b) Corresponding IR emissivity as a function of IWP under the same assumptions as in (a).

clouds by 0.03 to 0.06 and improved the agreement with the radiative transfer simulations. The comparison of the simulated and observed SW albedos provides a test of the microphysical parameterization of the consistency of the optical properties between the SW and LW domains. Three parameterizations of optical properties were tested in conjunction with different assumptions about ice crystal sizes (constant, increasing with IWP, and increasing with $\left.T_{\mathrm{cld}}\right)$. For the same IWP and $D_{e}$ the SW albedo is larger for cirrus made of ice crystal aggregates than for cirrus made of pristine crystals, whereas the LW emissivity is smaller. This can be explained by a smaller asymmetry and a lower extinction of ice crystal aggregates. By relating the cirrus IWP retrieved from the IR effective emissivity to the cirrus SW albedo, differences between the parameterizations are amplified and therefore more apparent in the observations.

From these analyses we conclude that SW albedos for large-scale semitransparent cirrus are the most realistic if one allows $D_{e}$ to increase with IWP, assuming pristine ice crystal shapes for IWP $<25 \mathrm{~g} \mathrm{~m}^{-2}$ and aggregates for larger IWP.

Acknowledgments. This work has been supported by the Commission of the European Community during the FP5 project CIRAMOSA (EVK2-2000-00597). The ScaRaB-ISCCP dataset as well as the SW ADMs have been created by Vincent Briand during his Ph.D. studies at LMD (Laboratoire de Météorologie Dynamique). The authors want to thank A. Baran, Q. Fu, and an anonymous reviewer for their thoughtful comments, which helped to improve considerably the clarity of the manuscript.

\section{REFERENCES}

Baran, A. J., 2003: Simulation of infrared scattering from ice aggregates using a size/shape distribution of ice cylinders. Appl. Opt., 42, 2811-2818.

- P. N. Francis, L. C. Labonnote, and M. Doutriaux-Boucher, 2001: A scattering phase function for ice cloud: Tests of applicability using aircraft and satellite multi-angle multiwavelength radiance measurements of cirrus. Quart. J. Roy. Meteor. Soc., 127, 2395-2416.

Bony, S., and K. A. Emanuel, 2001: A parameterization of the cloudiness associated with cumulus convection: Evaluation using TOGA COARE Data. J. Atmos. Sci., 58, 3158-3183.

Boudala, F. S., G. A. Isaac, Q. Fu, and S. G. Cober, 2002: Parameterization of effective ice particle size for high-latitude clouds. Int. J. Climatol., 22, 1267-1284.

Bréon, F.-M., 1992: Reflectances of broken cloud fields: Simulation and parameterization. J. Atmos. Sci., 49, 1221-1232.

Briand, V., 2000: Vers une meilleure exploitation des observations satellitales pour l'étude de l' effet radiatif des nuages. Ph.D. thesis, University of Paris VI, 129 pp. [Available from C. J. Stubenrauch, LMD, Ecole Polytechnique, F-91128 Palaiseau CEDEX, France.]

Chédin, A., N. A. Scott, C. Wahiche, and P. Moulinier, 1985: The improved initialization inversion method: A high resolution physical method for temperature retrievals from satellites of the TIROS-N series. J. Climate Appl. Meteor., 24, 128-143.

Chevallier, F., F. Cheruy, N. A. Scott, and A. Chédin, 1998: A neural network approach for a fast and accurate computation of longwave radiative budget. J. Appl. Meteor., 37, 13851397.

Cusack, S., J. M. Edwards, and J. M. Crowther, 1999: Investigating 
$\mathrm{k}$ distribution methods for parameterizing gaseous absorption in the Hadley Centre Climate Model. J. Geophys. Res., 104, 2051-2057.

Donner, L. J., C. J. Seman, B. J. Soden, R. S. Hemler, J. C. Warren, J. Ström, and K.-N. Liou, 1997: Large-scale ice clouds in the GFDL SKYHI general circulation model. J. Geophys. Res., 102, $21745-21768$.

Edwards, J. M., and A. Slingo, 1996: Studies with a flexible new radiation code: I. Choosing a configuration for a large-scale model. Quart. J. Roy. Meteor. Soc., 122, 689-719.

_ S. Havemann, J.-C. Thelen, and A. J. Baran, 2007: A new Parameterization for the radiative properties of ice crystals: Comparison with existing schemes and impact in a GCM. Atmos. Res., 83, 19-34.

Fu, Q., 1996: An accuarate parameterization of the solar radiative properties of cirrus clouds for climate models. J. Climate, 9, 2058-2082.

_, P. Yang, and W. B. Sun, 1998: An accurate parameterization of the infrared radiative properties of cirrus clouds in climate models. J. Climate, 11, 2223-2237.

Garrett, T. J., H. Gerber, D. G. Baumgardner, C. H. Twohy, and E. M. Weinstock, 2003: Small, highly reflective ice crystals in low-latitude cirrus. Geophys. Res. Lett., 30, 2132, doi:10.1029/ 2003GL018153.

Heymsfield, A. J., 1977: Precipitation development in stratiform ice clouds: A microphysical and dynamic study. J. Atmos. Sci., 34, 367-381.

— , and C. M. R. Platt, 1984: A parameterization of the particle size spectrum of ice clouds in terms of the ambient temperature and the ice water content. J. Atmos. Sci., 41, 846-855.

Ivanova, D., D. L. Mitchll, W. P. Arnott, and M. Poellot, 2001: A GCM parameterization for bimodal size spectra and ice mass removal rates in mid-latitude cirrus clouds. Atmos. Res., 5960, 89-113.

Kandel, R. S., and Coauthors, 1998: The ScaRaB earth radiation budget dataset. Bull. Amer. Meteor. Soc., 79, 765-783.

Key, J., and A. Schweiger, 1998: Tools for atmospheric radiative transfer: Streamer and FluxNet. Comput. Geosci., 24, 443451.

Korolev, A. V., G. A. Isaac, I. P. Mazin, and H. W. Baker, 2001: Microphysical properties of continental clouds from in-situ measurements. Quart. J. Roy. Meteor. Soc., 127, 2117-2151.

Kristjânsson, J.-E., J. M. Edwards, and D. L. Mitchell, 2000: The impact of a new scheme for the optical properties of ice crystals on the climates of two GCMs. J. Geophys. Res., 105, $10063-10079$.

Li, Z., and A. Trishchenko, 1999: A study towards an improved understanding of the relationship between visible and shortwave measurements. J. Atmos. Oceanic Technol., 16, 347360.

Loeb, N. G., F. Parol, J.-C. Buriez, and C. Vanbauce, 2000: Topof-atmosphere albedo estimation from angular distribution models using scene identification from satellite cloud property retrievals. J. Climate, 13, 1269-1285.

_, K. Loukachine, N. Manalo-Smith, B. A. Wielicki, and D. F. Young, 2003: Validation of the top-of-atmosphere short- and longwave radiative flux estimation from the Clouds and the Earth's Radiant Energy System instrument on the tropical rainfall Measuring Mission satellite. Part II: Validation. $J$. Appl. Meteor., 42, 1748-1769.

Loukachine, K., and N. G. Loeb, 2003: Application of an artificial neural network simulation for top-of-atmosphere radiative flux estimation from the Clouds and the Earth's Radiant En- ergy System (CERES). J. Atmos. Oceanic Technol., 20, 1749_ 1757.

Macke, A., R. Dlhopolsky, J. Mueller, R. Stuhlmann, and E. Raschke, 1995: A study on bidirectional reflection functions for broken cloud fields over ocean. Adv. Space Res., 16, 50-58.

McFarlane, N. A., G. J. Boer, J. P. Blanchet, and M. Lazare, 1992: The Canadian Climate Centre second-generation general circulation model and its equilibrium climate. J. Climate, 5, 1013-1044.

McFarquar, G. M., and A. J. Heymsfield, 1996: Microphysical characteristics of three anvils sampled during the Central Equatorial Pacific Experiment (CEPEX). J. Atmos. Sci., 53, 2401-2423.

McPeters, R. D., D. F. Heath, and P. K. Bhartia, 1984: Average ozone profiles for 1979 from the NIMBUS-7 SBUV instrument. J. Geophys. Res., 89, 5199-5214.

Minnis, P., P. W. Heck, and D. F. Young, 1993: Inference of cirrus cloud properties using satellite-observed visible and infrared radiances. Part II: Verification of theoretical cirrus radiative properties. J. Atmos. Sci., 50, 1305-1322.

Mishchenko, M. I., 1991: Light scattering by randomly oriented axially symmetric particles. J. Opt. Soc. Amer., 8A, 871-882.

Mitchell, D. L., A. Macke, and Y. Liu, 1996: Modeling cirrus clouds. Part II: Treatment of radiative properties. J. Atmos. Sci., 53, 2967-2988.

Nussenzveig, H. M., and W. J. Wiscombe, 1980: Efficiency factors in Mie scattering. Phys. Rev. Lett., 45, 1490-1493.

Rädel, G., C. J. Stubenrauch, R. Holz, and D. L. Mitchell, 2003: Retrieval of effective ice crystal size in the infrared: Sensitivity study and global measurements from the TIROS-N Operational Vertical Sounder. J. Geophys. Res., 108, 4281, doi:10.1029/2002JD002801.

Rossow, W. B., and R. A. Schiffer, 1999: Advances in understanding clouds from ISCCP. Bull. Amer. Meteor. Soc., 80, 22612287.

—, A. W. Walker, D. Beuschel, and M. Roiter, 1996: International Satellite Cloud Climatology Project (ISCCP): Description of new cloud datasets. WMO/TD-No.737, World Climate Research Programme (ICSU and WMO), Geneva, Switzerland, 115 pp.

Schlimme, I., A. Macke, and J. Reichardt, 2005: The impact of ice crystal shapes, size distributions, and spatial structures of cirrus clouds on solar radiative fluxes. J. Atmos. Sci., 62, 22742283.

Scott, N. A., and Coauthors, 1999: Characteristics of the TOVS Pathfinder Path-B dataset. Bull. Amer. Meteor. Soc., 80, 2679-2701.

Stith, J. L., J. E. Dye, A. Bansemer, A. J. Heymsfield, C. A. Grainger, W. A. Petersen, and R. Cifelli, 2002: Microphysical observations of tropical clouds. J. Appl. Meteor., 41, 97-117.

Stubenrauch, C. J., G. Sèze, N. A. Scott, A. Chédin, M. Desbois, and R. S. Kandel, 1996: Cloud field identification for Earth Radiation Budget studies. Part II: Cloud field classification for the ScaRaB radiometer. J. Appl. Meteor., 35, 428-443.

- A. Chédin, R. Armante, and N. A. Scott, 1999a: Clouds as seen by infrared sounders (3I) and imagers (ISCCP). Part II: A new approach for cloud parameter determination in the $3 \mathrm{I}$ algorithms. J. Climate, 12, 2214-2223.

- W. B. Rossow, N. A. Scott, and A. Chédin, 1999b: Clouds as seen by infrared sounders (3I) and imagers (ISCCP). Part III: Spatial heterogeneity and radiative effects. J. Climate, 12, 3419-3442.

—, V. Briand, and W. B. Rossow, 2002: The role of clear-sky 
identification in the study of cloud radiative effects: Combined analysis from ISCCP and the Scanner of Radiation Budget. J. Appl. Meteor., 41, 396-412.

, F. Eddounia, and G. Rädel, 2004: Correlations between microphysical properties of large-scale semi-transparent cirrus and the state of the atmosphere. Atmos. Res., 72, 403-423.

, - — , and L. Sauvage, 2005: Cloud heights from TOVS PathB: Evaluation using LITE observations and distributions of highest cloud layers. J. Geophys. Res., 110, D19203, doi:10.1029/2004JD005447.

—, A. Chédin, G. Rädel, N. A. Scott, and S. Serrar, 2006: Cloud properties and their seasonal and diurnal variability from TOVS Path-B. J. Climate, 19, 5531-5553.

Suttles, J. T., B. A. Wielicki, and S. Vemury, 1992: Top-ofatmosphere radiative fluxes: Validation of ERBE scanner inversion algorithm using Nimbus-7 ERB data. J. Appl. Meteor., 31, 784-796.

Van de Hulst, H. C., 1957: Light Scattering by Small Particles. Wiley, $470 \mathrm{pp}$.

Viollier, M., R. S. Kandel, and P. Raberanto, 1995: Inversion and space-time averaging algorithms for ScaRaB (Scanner for
Earth Radiation Budget) comparison with ERBE. Ann. Geophys., 13, 959-968.

Volkovitskiy, O. A., L. N. Pavlova, and A. G. Petrushin, 1980: Scattering of light by ice crystals. Atmos. Ocean Phys., 16, 90-102.

Wylie, D. P., and W. P. Menzel, 1999: Eight years of cloud statistics using HIRS. J. Climate, 12, 170-184.

Yang, P., and K. N. Liou, 1996: Geometric-optics-integralequation method for light scattering by non-spherical ice crystals. Appl. Opt., 35, 6568-6584.

— , and - 1998: Single-scattering properties of complex ice crystals in terrestrial atmosphere. Contrib. Atmos. Phys., 71, 223-248.

Zdunkowski, W. G., R. M. Welch, and G. Korb, 1980: An investigation of the structure of typical two-stream methods for the calculation of solar fluxes and heating rates in clouds. Beitr. Phys., 53, 147-166.

Zell, A., and Coauthors, 1995: Stuttgart Neural Network Simulator (SNNS) user manual, version 4.1. University of Stuttgart, $312 \mathrm{pp}$. [Available online at http://www-ra.informatik.unituebingen.de/SNNS/.] 